\title{
Intra-labour Strategic Commitment
}

\author{
by \\ Matthew Nolan
}
A thesis
submitted to the Victoria University of Wellington in fulfilment of the requirements for the degree of Master of Commerce and Administration in Economics.

Victoria University of Wellington 2009 


\begin{abstract}
This thesis explores a strategic investment motive for the choice of skilled labour (management). Using the case study of department store competition, we argue that management is an observable and irreversible input. This allows firms to use it to obtain a first-mover advantage in oligopolistic interactions. We find that, given complementarities of labour inputs, firms will hire excess management relative to the cost-minimising input bundle. This idea is first illustrated with a simple two-stage example. We then show that over-management also holds in a more realistic setting with infinitely-lived firms facing finite adjustment costs.
\end{abstract}




\section{Acknowledgments}

Many thanks to my primary supervisor Vladimir Petkov, for the advice and time spent helping me prepare my thesis. His help was instrumental in completing the thesis. Thanks to my secondary supervisor Paul Calcott for his analysis and ideas, which helped to add a great deal to the final thesis. And thanks to Victoria University of Wellington for giving me the opportunity to work on this thesis. Special thanks to my family, Veronica, Sarah, and Patrick Nolan for their support. 


\section{Contents}

\begin{tabular}{|ll}
\hline Acknowledgments & i
\end{tabular}

$\begin{array}{lll}1 & \text { Introduction } & 1\end{array}$

2 Preliminaries 4

2.1 Assumptions Primer . . . . . . . . . . . . . . . 5

2.2 Elements of the Model . . . . . . . . . . . . . . 6

2.3 Employees as Inputs $\ldots \ldots \ldots 6$

2.3.1 What type of inputs are managers and workers? . . . 8

2.3 .2 Managers ................. 8

2.3 .3 Workers . . . . . . . . . . . . . . . . 12

\begin{tabular}{|lll|}
\hline 2.3 .4 & How does the production process involving man- \\
\hline
\end{tabular}

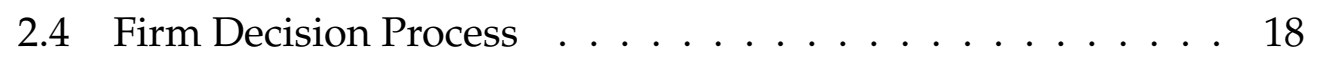

2.4.1 What sort of horizon is applicable to firm decision making? ................... 18

2.5 Industry $\ldots \ldots \ldots \ldots$

2.5.1 Are firms facing an oligopolistic market or monopolistic competition? . . . . . . . . . . . 19

2.5.2 How are the firms' choice variables related to the structure of the industry? . . . . . . . . . . . 22 
2.6 Core Assumptions . . . . . . . . . . . . . 26

2.6 .1 Grouping the Assumptions . . . . . . . . . . 27

3 Model One 28

3.1 Commitment value of management . . . . . . . . . . 28

$3.1 .1 \quad$ Irreversibility . . . . . . . . . . . . . . . . . 29

3.1 .2 Observability . . . . . . . . . . . . 30

3.1.3 The effect of management on output . . . . . . . . . . 31

3.2 Summary argument . . . . . . . . . . . . . . . 32

3.3 General setting . . . . . . . . . . . . . . . 32

3.4 Cost minimising input bundles . . . . . . . . . . . . 33

3.5 Static competition . . . . . . . . . . . . . 34

3.6 Unilateral commitment . . . . . . . . . . . . . . . . 36

3.6 .1 Motivation . . . . . . . . . . . . . 36

3.6 .2 Commitment as a choice . . . . . . . . . . . 37

3.6.3 The unilateral commitment game. . . . . . . . . . 38

3.6 .4 Over-management . . . . . . . . . . . . . 43

3.7 Bilateral commitment . . . . . . . . . . . . . . . . . . 44

3.7 .1 Stage $2 \ldots \ldots \ldots \ldots \ldots$

3.7 .2 Stage $1 \ldots \ldots \ldots \ldots \ldots$

3.7.3 Comparison with the simultaneous-move game . . . 46

3.7.4 Over-management and cost minimisation in the sequential game ................... 48

3.8 Cobb-Douglas example . . . . . . . . . . . . . . . 48

3.8.1 Simultaneous-move benchmark . . . . . . . . . . . . 49

3.8.2 Bilateral commitment game . . . . . . . . . . 50

3.8 .3 General Input Prices . . . . . . . . . . . . . . . . 52 
CONTENTS iv

3.9 Comparison to Literature . . . . . . . . . . . . . . 53

3.10 Conclusion . . . . . . . . . . . . . . . . 53

4 Weakening the assumptions of model one 54

$4.1 \quad$ Extending the horizon of the game . . . . . . . . . . . 54

4.1 .1 Interpretation of the infinite horizon game . . . . . 55

4.1 .2 Infinite horizon model . . . . . . . . . . . . 57

$\begin{array}{lll}5 & \text { Model Two } & 61\end{array}$

5.1 Finite adjustment costs of management . . . . . . . . . . 61

5.1 .1 Discussion . . . . . . . . . . . . . 61

5.1 .2 Summary argument . . . . . . . . . . . 62

5.2 Notation . . . . . . . . . . . . . . . . . 63

5.2 .1 Choice variables . . . . . . . . . . . . 63

5.3 Infinite horizon model . . . . . . . . . . . . . . . 63

$5.3 .1 \quad$ Setup . . . . . . . . . . . . . . 63

5.3 .2 Analysis . . . . . . . . . . . . . 6 65

5.4 Motivation for the numerical example . . . . . . . . . . . 69

5.4.1 Two-period example with perfect substitutability . . 69

5.4 .2 Two-period example with quadratic costs . . . . . . . 73

5.5 Infinite horizon linear-quadratic example . . . . . . . . . 76

5.5 .1 The impact of the adjustment cost . . . . . . . . 77

5.5 .2 The impact of the discount factor . . . . . . . . . 79

5.5 .3 The impact of product heterogeneity . . . . . . . . 79

5.6 Conclusion . . . . . . . . . . . . . . . . . . . . . 81

$\begin{array}{lll}6 \text { Conclusion } & 82\end{array}$ 
CONTENTS V v

$\begin{array}{lll}7 & \text { Appendix } & 84\end{array}$

7.1 Appendix A . . . . . . . . . . . . . . . 84

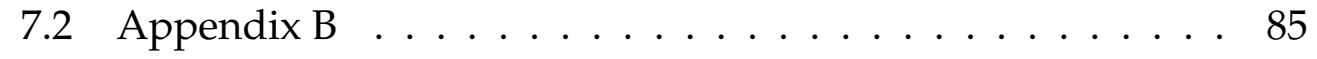

7.2 .1 Increasing the number of firms . . . . . . . . . . 85

7.3 Appendix C . . . . . . . . . . . . . . 86

7.4 Appendix D . . . . . . . . . . . . . . . 87

$7.4 .1 \quad$ Deriving Firm $\mathrm{A}^{\prime}$ s Euler equation. . . . . . . . . . 87

7.5 Appendix E . . . . . . . . . . . . . . . . . . 89

7.5.1 Euler equations for the four state model . . . . . . . . 89 


\section{Chapter 1}

\section{Introduction}

The question of how firm's choose their labour input has been widely discussed in the social sciences. Labour has a special role among all inputs. Some of the primary ways it differs from other inputs are:

1. The person who sells the input is the input.

2. It is one of the few inputs used in all forms of production

3. The differentiability of the labour input is remarkable with each person providing different levels of effort, intrinsic skill, and knowledge to the productive process.

4. It is the input that most of society uses to gain income and create wealth.

As a result, a full understanding of the functioning of the labour input is an essential part of any attempt to understand the functioning of society as a whole.

The goal of this thesis is to determine whether the labour input of a firm could in fact be determined through a game of strategic commitment using different types of labour inputs. This is a situation where the combination of labour types could be manipulated to convey some type of strategic advantage to the firm.

We will illustrate the potential for strategic commitment using a specific case study, department store competition. In this case firms are assumed 
to choose two types of inputs, a committable input (management) and a non-committable input (workers). By illustrating that firms may over-hire managers relative to the cost minimising choice for a given level of output we can show that the idea of strategic commitment could explain such a situation.

The case where firms over-hire managers will be called over-management. By describing over-management this thesis will add several things to the literature:

1. A clear framework for viewing the interaction of skilled and unskilled labour,

2. A novel description of the labour input, through the strategic interaction of types of labour,

3. A description of why firms may rationally overuse skilled labour relative to the efficient allocation,

4. An illustrative example of when a rational, profit maximising firm may not choose their set of inputs in a way that minimises costs. This would show that the duality of cost minimisation and profit maximisation does not necessarily hold among labour types,

5. A testable hypothesis on the behaviour of the labour input.

The testable hypothesis will be: is there over-management in the department store industry. 1 . Over-management refers to a situation where the ratio of managers to other inputs is greater than the static cost minimisation would suggest. Although not easily quantifiable ${ }^{2}$, over-management is a phenomena that seems intuitively appealing. Such a phenomena provides a strong test case for using strategic investment models in terms of labour.

The aim of the following sections is to provide an explanation of overmanagement, and therefore provide a test case for the the possibility of a strategic investment motive among labour inputs. Chapter 2 describes the elements of the firm required for economic description. Chapter 3 provides a two-stage strategic investment model that leads to over-management.

\footnotetext{
${ }^{1}$ We were unable to find data with which to test this hypothesis. A suggestion of potential ways to test it is available in Appendix C

${ }^{2} \mathrm{An}$ issue that is briefly touched upon in Appendix $\mathrm{C}$
} 
Chapter 4 describes problems with the two-stage model. Chapter 5 provides a dynamic model of strategic investment to explain over-management which overcomes some of the issues with the two-stage result. Finally Chapter 6 concludes. 


\section{Chapter 2}

\section{Preliminaries}

For strategic investment to be effective, it must both influence the choices of the firm's competitors and be credibly committed to a given level. The combination of interdependence (Watson 2002) of firms' actions and commitment provides producers with an incentive to choose investment strategically in order to gain a competitive advantage. The objective of this chapter is to argue that management can be viewed as a strategic investment resource. This will allow us to use common economic models of sequential choice to explain over-management.

Before discussing the nature of management, we need to provide a description of the setting where management operates. For this purpose, we must specify the individual elements of this setting, including managers. An environment that includes multiple firms is referred to as a social situation. To model such situations, we use the methodology of game theory.

Within the field of game theory, we will focus on a narrower range of models that answer the question, what will be accepted by a rational agent (Greenberg 1990)? Economic agents can be firms or individuals. The objective of a rational agent is to maximise their utility. The questions of what gives an agent utility and how to measure it may never be clearly answered. However, when analysing the decision making process of firms, we often assume that utility maximisation corresponds to profit maximisation.

For a firm's investment to influence the choice of other firms, it must influence their profits. We will discuss the mechanism of these interactions 
over the course of this chapter.

\subsection{Assumptions Primer}

To clearly describe strategic investment, we must state the assumptions that underlie our model. They define the boundaries of what this model explains and pin down the domain of what constitutes a firm. The more rigid the assumptions required for our result, the fewer situations they will be applicable to. Conversely, the larger the domain, the more likely it is that our result will reflect reality (Hamminga 1982). Consequently, the goal of our modeling approach is to expand this domain as much as possible. To enlarge the domain of our model, we need to use the least rigid assumptions that deliver our result. Therefore, when modeling a situation, it is important to recognise which assumptions are central to our results.

Maki (1994) discusses the different types of assumptions within a model. He divides them into two categories: core assumptions and peripheral assumptions. The core assumptions represent the central forces that drive the results of the model. They are crucial for the analysis. Peripheral assumptions are intended to simplify the working of our model by neutralis(ing) factors that are not regarded as central or essential (Maki 1994). In order to evaluate a model, it is important to investigate which are the core assumptions, and then defend them. The stronger our defense, the more plausible our hypothesis is..$^{1}$

According to Maki, the realism of the peripheral assumptions is not necessarily important, as they are not the causal factors of a given phenomenon. Examples of such assumptions in the literature include homogenous goods and deterministic demand.2

Given the separate treatment that core and peripheral assumptions receive, it is essential to be able to clearly differentiate between them. This is the aim of the following discussion of elements of the model.

\footnotetext{
${ }^{1} \mathrm{~A}$ difficulty we run into is the fact that what constitutes our core assumptions is often subjective. Thus, it is important to be able to justify our definition of the set core assumptions.

${ }^{2}$ Although these specific assumptions are not always peripheral to the results.
} 


\subsection{Elements of the Model}

When modeling a social situation, it is important to understand what realworld phenomenon the model attempts to explain. Describing firm competition will require the specification of all relevant elements. However, we will focus on the assumptions of the game that may be contentious. These assumptions are related to three of the elements of the environment: employees / inputs, the industry, and the decision process of the firm. They are captured by the following questions.

\section{Employees and inputs}

- What are managers and workers?

- How does the production process involving managers and workers function?

\section{Firm Decision Process}

- What sort of horizon is applicable to firm decision making: static, two-period, or infinite horizon?

\section{Industry}

- Do firms operate in an oligopolistic market or engage in monopolistic competition?

- How are the firms' choice variables related to the industry structure?

\subsection{Employees as Inputs}

Like land and capital, labour is a factor of production. However there is a tendency to treat the labour input differently. The reason is that, unlike other production factors, workers and managers can make conscious decisions. For example, a person decides how hard to work, while a piece of machinery does not. The employees' choice of work effort affects the 
productivity of the labour input, which creates a clear distinction between the behaviour of labour and non-labour inputs.

Because of this fundamental difference, the literature has used different methods to analyse labour. Sometimes the interaction between labour and non-labour inputs is treated in a mechanical fashion, as a black box process leading from a set of inputs to a set of outputs. However, there is also literature that performs a detailed analysis of the labour input by itself. The focus on the cognitive dimension associated with labour has led to variety of game theoretic models that try to explain how this input is incorporated in the production process. An example of this type of modeling is efficiency wages (Shapiro \& Stiglitz 1984).

In addition to the cognitive element of the labour input, there is also substantial research on the differentiation within labour. All employees ultimately have very different skills and roles. Because of these heterogeneities, the labour input can be decomposed into labour types.

Along these lines, one simplistic approach is to divide the labour input into skilled and unskilled categories (Keren \& Levhari 1983). Although this decomposition is rather simple to be realistic, we will make use of it in this thesis. Furthermore, the distinction between skilled and unskilled labour fits the description put forward by the New Zealand Department of Labour, namely:

"Highly skilled" includes managers and professionals; "skilled" includes technicians / semi-professionals and trades; and "semiskilled/elementary" includes all other occupations. ${ }^{3}$

This suggests that such a decomposition may be policy relevant. In the thesis we will use similar classification, distinguishing between managers (as skilled labour) and workers (as unskilled labour). Another source of heterogeneity stems from the difference between specific and general skills. The roles employees take on depend on the industry, as does the specificity of the skills required for these roles. Finally, the specificity and the cost of a given skill set are themselves important elements of the description of labour inputs.

\footnotetext{
${ }^{3}$ http://dol.govt.nz/publications/lmr/lmr-Skills.asp
} 


\subsubsection{What type of inputs are managers and workers?}

In order to describe managerial and worker inputs, we have to establish their characteristics. This necessitates an investigation of the role of these inputs in the production process.

In many situations it is unclear whether managers are more skilled and have more rigid contracts relative to workers. To get past this issue, we will focus on the labour inputs of a department store, which seem to exhibit these properties.

Once we analyse the basic model, we will attempt to generalise our results. This will give us the attributes of the manager/worker relationship that are necessary for over-management.

\subsubsection{Managers}

\section{The branch level manager}

The issue of what constitutes management is an important question in social sciences. In economics, managers are often assumed to maximise their own utility in an environment fraught with principal-agent conflicts. However, in management science, the strategic management approach depicts managers as players whose incentives are aligned to profit maximisation, but have to make decisions in an uncertain environment. In both disciplines, managers are seen as active players who make strategic decisions within the structure of a firm.

The active, and extremely broad, description of managers that is commonly accepted in economics is typified by this quote from Fershtman \& Kalai (1993):

Managing corporations is a complex and time consuming task. Managers need to evaluate changing market conditions, contemplate competitive strategies, decide on new products, production technologies, and new markets, and so forth.

Although this view correctly describes high level management in a large organisation, it does not seem realistic for managers at lower levels. At 
different steps in the hierarchy of the firm, staff are given separate, specialised tasks. The focus of this thesis is primarily on the branch level of firms with a large hierarchical structure.

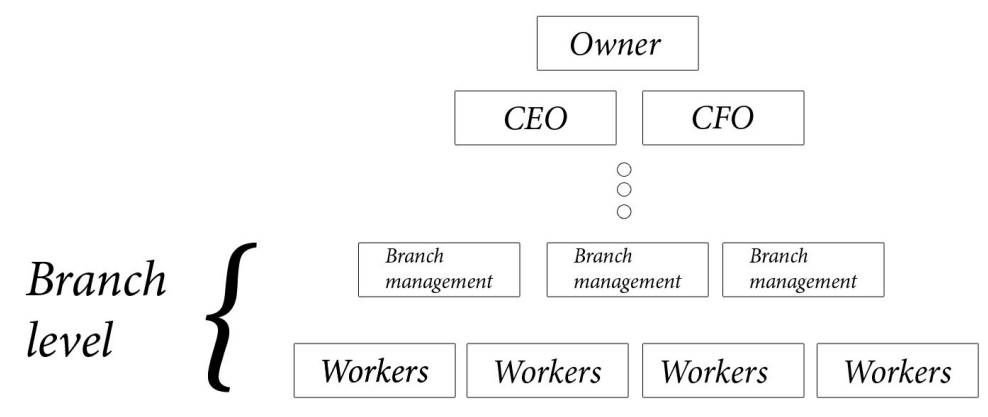

At the branch level, managers would not be making decisions about technology or new products/markets, but would react to changes in the market conditions and determine hiring levels. Even these tasks of branch level managers would be constrained by decisions further up the chain of command, such as the hiring budget.

Ultimately, the managerial input considered here has a more specific role than the manager described by Fershtman \& Kalai (1993). The scope of this specificity, and how it fits into the production process, are important properties of the managerial input.

\section{Strategic delegation}

Before putting forward assumptions about the specific role of branch level managers, it is important to mention another area of research known as strategic delegation (Skilivas 1987) (Fershtman \& Judd 1987). In this literature, the owner of the firm delegates decision-making to a manager, and then designs a contract that allows him to use management strategically by setting up appropriate incentives.

The strategic delegation literature does look at a form of commitment, but it is fundamentally different from the type of commitment considered here. The difference is that strategic delegation works by influencing the actions of managers, while in our model commitment is based on the number of employed managers. 


\section{The role of branch level managers}

In the aforementioned literature, there is implicitly some type of principalagent conflict between the owner of the firm and its manager. Assuming that their relationship can be framed by a principal agent problem, and abstracting from other production factors, we argue that the owner's choice of managers and managerial contracts must affect the firm's level of production. Since agents are rational, we know that the contractual relationship between the owner and the mangers at each layer of the firm will be optimal. When we model the firm's choice of managerial input, we will circumvent these issues by assuming that managerial contracts and wage rates are fixed exogenously.

As we have abstracted from the higher layers of management, our interest now lies with the relationship between the branch level managers and the workers. We assume that the primary role of managers is supervision of workers. A similar assumption was also made by Alchian \& Demsetz (1972), who studied production in a firm where workers can shirk. This assumption presupposes that a major role of management is to supervise workers, thus increasing their productivity.

To provide empirical support for over-management, we will focus on department store competition in New Zealand. One major New Zealand department store that has grown substantially over the past decade is the Warehouse. When advertising for the position of assistant manager, they identified the following skills as appropriate:

"The key attributes we are looking for are:

- Previous experience in leading a large team within a retail environment.

- Individuals who can understand, and have the ability to communicate and model the visions and values of The Warehouse Ltd.

- An ability to build and maintains positive working relationships with other areas of the business.

- The ability to maintain and enhance the current store environment.

${ }^{4}$ http://www.thewarehouse.co.nz/content.aspx?id = 100020744\#AssStoMan, 4th of October 2006 
- An ability to communicate at all levels through written and verbal communication.

- An ability to achieve operational goals.

- The ability to demonstrate superior management competencies."

Other department stores in New Zealand (Farmers $5^{5}$ and Briscoes ${ }^{6}$ ) define the role of managers in a similar way.

From the above description it is clear that the ability to communicate with staff is a highly valued skill for managers in the retail industry. The importance of communication over administrative skills implies that supervision, and other attributes that increase the marginal product of workers (such as motivation), are the primary skills required from branch level managers.

\section{Specificity and supervision}

The managerial task of supervision requires specific skills. Although some people may be naturally disposed to being supervisors, firms usually spend a large amount of time and money training their staff to supervise. This investment in human capital makes managers inherently costly to replace. Furthermore, managers sign full time contracts. Given New Zealand labour laws, this makes them even costlier to remove.

Costly replacement and removal of managers relates to the difficulty of changing the extensive margin of the managerial resource. The extensive margin is the discrete choice of an aggregate variable. In the context of this thesis, it refers to the choice of the number of managers (and not the number of manager hours). The difficulty of changing the extensive margin implies that the number of managers may be costly or impossible to adjust in the short run.

Similarly, the intensive margin is defined as the continuous choice of an aggregate variable. In this context, it corresponds to the choice of managerial hours. The difficulty associated with changing the hours each manager works implies that it is costly or impossible to adjust in the short run.

\footnotetext{
${ }^{5}$ http: / / www.farmers.co.nz/careers-storeroles.html, October 2006

${ }^{6}$ http: / / www.briscoes.co.nz/frames.asp?cont=careers, March 2008
} 
Most managers receive a fixed salary that does not depend on the hours worked. As a result, they have no incentive to increase their hours of work. Also, they are heavily supervised from above, so they are unable to work less. This rigidity in the hours of work implies further stickiness in the intensive margin.

Finally, our models will assume a perfectly competitive managerial labour market. That is, the other firms' choice of management does not affect the cost of this resource. This simplification is made in order to eliminate other mechanisms that would generate over-management. ${ }^{7}$

\section{Conclusion}

The important assumptions about managers can be summarised as follows:

- Their main role is supervision and motivation of staff.

- The number of managers is costly to adjust.

- The number of manager hours is costly to adjust.

- The labour market for managers is perfectly competitive.

We can therefore define the manager input as follows.

Managerial Input: the number of effective manager hours used during a period of production.

\subsubsection{Workers}

The worker input in our model is similar to what is commonly considered in the general economic literature. Workers provide the final step in the production process before the good is sold to consumers. In terms of retail stores, this is the staff who process transactions of goods to consumers (e.g. checkout staff).

\footnotetext{
${ }^{7}$ E.g. through a pecuniary externality on the other firms' costs.
} 
Staff at this level of the firm can be skilled or unskilled. Our interest lies with workers who are unskilled. In other words, the firm has not previously invested in increasing their productivity ${ }^{8}$ Thus, it is relatively inexpensive to replace them. Replacement is made even easier by the fact that many workers in a department store are on part time or casual contracts. The low cost of replacing and removing workers implies that the extensive margin (i.e. the number of workers) is relatively adjustable.

Furthermore, unskilled workers are often paid an hourly wage, and their hours are partially determined by weekly rosters. This implies that their number of work hours can be adjusted by the firm. As a result, the intensive margin of the worker input is not fixed.

Finally, we assume a perfectly competitive worker labour market. That is, the other firms' choice of workers does not affect the cost of this input.

\section{Definition of the worker input}

The important assumptions about workers are:

- They sell the retail product to consumers

- The number of workers is relatively costless to adjust

- Work hours are relatively costless to adjust

- The labour market for workers is perfectly competitive.

Therefore, we give the following definition of worker input.

Worker Input: the number of effective worker hours during a period of production.

\subsubsection{How does the production process involving managers and workers function?}

Even though managers and workers are assumed to be separate inputs, they influence each other in the production process. Papers by Alchian

\footnotetext{
${ }^{8}$ To be precise, this does not imply that they have no ability.
} 
\& Demsetz (1972) and Holmstrom (1982) have established that the interaction between managers and workers can take the form of a principalagent relationship, where production is the result of team work. In this literature, there is a principal whose interests are aligned with those of the firm, and an agent whose interests may not be aligned, but whose action affects profits.

In our model, we could view the set of managers as principals, and the set of workers as agents. The workers are required to produce a good, but they dislike exerting the effort that is required for production. The principal/manager supervises the workers, and punishes them if they are caught exerting less than the required effort. Such supervision motivates workers to work harder. This is akin to the efficiency wage solution to the principal-agent problem, where market wages reflect an "expected cost" of the choice to shirk.

In models of efficiency wages, each combination of managers and workers determines a level of output, but it does so through a principal-agent interaction. The relationship between the labour inputs and output can also be described by a production function, in the same way as with other inputs.

\section{Managerial incentives}

One problem with our approach is the assumption that managerial incentives are aligned with those of the firm. There could be another principalagent conflict between low-level managers and managers that are higher up the firm. In some sense, there are principal-agent conflicts within every step vertically up the hierarchy. This occurs because the utility maximising choice of an individual employee is never perfectly aligned with the owner's objective.

Papers by Jensen \& Meckling (1976) and Holstrom \& Milgrom (1991) describe how principal-agent conflicts can be at least partially solved through the use of incentive contracts that tie managerial rewards to effort. This idea is fundamentally different from the supervision problem. While efficiency wages rely on supervision and punishment, incentive contracts provide motivation by offering wages that depend on variables correlated with the agent's effort. Incentive contracts are often given to high level 
managers, but are virtually absent from the branch level of many firms (Calvo \& Wellisz 1979). This suggests that some other mechanism forces branch level managers to exert effort.

The literature on the hierarchy of the firm (Williamson (1967), Alchian \& Demsetz (1972)) supports our claim. Calvo \& Wellisz (1978) and Calvo \& Wellisz (1979) argue that incentive contracts are more important for higher-level managers. Fundamentally, the further up the hierarchy of the firm the employee is, the greater the impact of their effort on total production. This is because they are able to influence the marginal product of a greater number of employees..$^{9}$ Incentive contracts are not as important for the management layer considered here: efficiency wages are sufficient to extract effort from managers.

Branch level managers are usually supervised by senior management. This supervision is enough to get them to put effort into supervising the workers underneath. At the base level of the firm, the owner will hire managers to supervise staff, knowing that this will increase worker effort. A similar process occurs further up the firm. Calvo \& Wellisz (1979) argues that as we move up in the hierarchy, incentive contracts become more important, and supervision less so. According to Calvo \& Wellisz (1979), we can also analyse the different layers of the firm individually, by treating external impacts as exogenous factors.

We have now established the separability of layers within the firm, as well as the fact that the higher levels of the firm are structured to get branch managers to provide "optimal effort". So when analysing the branch level, we can abstract from higher level managers. The choices further up the firm will have implications for the production function, but they will be treated as sunk by the time when output is chosen at the branch level of the firm.

\footnotetext{
${ }^{9}$ However, these incentives may be ignored simply because the degree of effort managers put in may depend more on natural disposition than on the contract given to them. This argument further justifies the specificity of the managerial input, but we will not use it to defend the lack of incentive contracts in our manager/worker relationship.
} 


\section{Worker-manager input relationship}

The above argument suggests that the relationship between managers and workers in a principal-agent setting (akin to the efficiency wage literature) will define a "technology" combining managerial and worker inputs that satisfies the typical properties of a production function. These properties are as follows.

- The choice of inputs should affect output.

- Output should be monotonically increasing in all inputs.

- Each input's impact on output should diminish as the amount of the input used increases (holding all else constant). Thus, both inputs have a declining marginal product.

The assumptions of a monotonically increasing production function and the falling marginal product of the input are made for convenience, and are common in the existing literature.

Consider the following simple example. Take a risk neutral worker who must choose between two effort levels, low and high. If they are not caught shirking, or are observed to be working hard, they are paid a wage $w$. Otherwise they are paid 0 . The agent's cost of high effort is $e(e>0)$, while the cost of low effort is 0 . Workers choose how much effort to exert once in the production phase. The probability of being caught when shirking is equal to $P(M): R^{+} \rightarrow(0,1)$, where $M$ is the number of managers. Assume that $P(M)$ is an increasing function.

The incentive constraint for working hard takes the form

$$
w P(M) \geqslant e
$$

We see that the higher the wage is, or the more managers there are, the harder a worker will work. This suggests that output will be increasing in the productivity of both workers (as their effort generates the output) and managers (as they motivate higher worker effort). Calvo \& Wellisz (1979) and Shapiro \& Stiglitz (1984) have argued that this result holds in a broad class of settings, while Machin \& Manning (1992) have shown that there is empirical evidence for this intra-firm phenomenon. 
To summarise, the principal-agent view allows us to model management and workers as inputs. This observation is important as it allows us to define a production function that translates these inputs to an output. Furthermore, it will allow us to quantify over-management.

\section{Complementary inputs}

Another important aspect of the relationship between managers and workers is revealed by looking at how the production process works. In the case of managers, we have a production factor that will put in a set amount of effort at a fixed wage (Rosen 1982). Their role is to supervise workers at the firm's base. ${ }^{10}$ Supervision increases the workers' effort. ${ }^{11}$ The relationship between managers and workers can be viewed as a relationship between two inputs that are complements in production. The more managers there are, the less the workers will shirk, and so the marginal product of workers will increase. Similarly, the more workers there are, the greater impact an additional manager will have on the marginal product of managers.

For a given level of output, managers and workers act as imperfect substitutes. Fundamentally, the more managers a firm has, the higher worker effort will be, and so the fewer workers will be needed to meet a given output target. Also, the more workers there are, the less effort is needed from each worker, and as a result the fewer managers are needed to extract that effort.

The complementarity and substitutability of these inputs is an important feature that will drive the results of this thesis.

\section{Conclusion}

When discussing labour inputs, we can make the following statements.

\footnotetext{
${ }^{10}$ Managers may have other roles, too. However, a large number of these additional roles are worked on further up the firms hierarchy (as more able staff are hired further up, more difficult jobs will be placed in their hands). Consequently, we can assume that the lowest level managerial staff are primarily supervisors

${ }^{11}$ There could be other reasons for the influence of management on the marginal product of workers. They may stem from the planning ability and experience of managers. Often they have more experience of the job than lower level employees and so advise them about improving their productive efficiency.
} 
- Management and workers can be viewed as distinct inputs

- Since management and workers can be considered inputs, we are able to define a production function that links them to output.

- Management influences production through its supervision role. By supervising workers, managers increase the marginal productivity of these workers.

\subsection{Firm Decision Process}

\subsubsection{What sort of horizon is applicable to firm decision making?}

The time horizon is an important element of any game. When defining the firm's objective as lifetime profit maximisation, it is important to state the time frame, so that "lifetime" is accurately defined. We distinguish between three types of timing: static, finite horizon, and infinite horizon. In a static model everything occurs at once. In a finite horizon model the game is played over a finite number of periods. The lifetime profit in such games is the sum of (discounted) profits over each period throughout the entire horizon. Finally, in an infinite horizon game there is an infinite number of periods. In this case the lifetime profit is the infinite discounted sum of profits realised in each period.

The appropriate time horizon is the one used by firms when they make decisions, not the actual horizon of a given market. This is a major issue in finite horizon games: if the endpoint is unknown, a finite game does not make sense, as it requires a definitive endpoint. Thus, a finite horizon model seems inappropriate for our analysis. In a static model, firms only produce and sell to consumers once, and all activities occur simultaneously. This is not a realistic description of most markets, and is especially problematic for the case of department stores/supermarkets. Thus, the only suitable option is that of an infinite horizon model.

However, a comparative static analysis of the static model, and its counterpart, the two-stage sequential choice model, could provide important insights into the problem of over-management. Papers by Spence (1977), 
and Brander \& Spencer (1983) show that a comparison between the static and sequential models can serve to illustrate over-investment in capital and R\&D. Since this is the direction taken by most of the literature, it seems appropriate to start with a two-stage model. Once our results have been established, we will revisit the issue of the time horizon and see if a move to an infinite horizon model adds value to the analysis.

\subsection{Industry}

The industry structure is an important determinant of firms' choices. Issues like the shape of demand, the type of competition and the number of firms are essential for input and output decisions. In our models, the most important requirement will be the strategic interdependence of firms' payoffs. It complicates producers' choices and distinguishes their problem from a simple operations research problem.

Firms selling identical or similar goods, along with a set of consumers of these goods, form a market. The interdependence of the firms' payoffs can give rise to strategic interactions in that market. A firm's action has strategic value if it influences the payoffs (and therefore the actions) of other firms. How the firm's choice of management and workers affect the payoffs of its competitors, and whether this in turn changes their choices of management and workers, is of fundamental interest. In order to explore this issue, we must establish the basic characteristics of the market.

\subsubsection{Are firms facing an oligopolistic market or monopo- listic competition?}

There are two main questions regarding our hypothetical market. Firstly, how many firms are in the market, and secondly, how similar are the goods these firms sell. Depending on the answers to these questions, we will consider a setting of oligopolistic competition or a setting of monopolistic competition. In the case of few (major) firms we have oligopolistic competition ${ }^{12}$, and with many firms and a differentiated product, we have monopolistic competition. The example of department stores should

\footnotetext{
${ }^{12}$ Note that oligopolies can produce differentiated as well as homogenous goods.
} 
shed light on the modeling choice of industry structure. The complicated nature of this industry suggests that both monopolistic competition and oligopoly could be potential fits.

\section{Monopolistic Competition}

In a monopolistically competitive industry many firms sell differentiated products. Although the term "many" is not directly quantifiable, the number of firms must be sufficient for them to be making normal profits in the long run. ${ }^{13}$ Also, an individual firm's choice of output should not influence the prices faced by the other firms in the industry. This is problematic for the purpose of our thesis, as it implies that the action of one player does not influence the actions of its competitors. As a result, there is no strategic incentive for the firm to increase their managerial input beyond the cost minimising level. If monopolistic competition described the industry best, strategic investment would not provide an explanation of over-management.

At first glance, monopolistic competition seems like a good description of how retail department stores compete at the branch level. At a given location, the branch competes with all other retail outlets, irrespective of their total size. As a result, retailers that only have one store nationwide can be equal competitors with a large organisation at the branch level. Furthermore, retailers tend to sell differentiated goods to consumers, making their product fall into some niche.

\section{Oligopoly}

In an oligopoly there are few firms selling substitutable products, and firm entry and exit do not fully respond to super-normal profits in the industry. The assumptions of few firms and of substitutable products deliver the strategic environment needed to generate value of commitment. This occurs because an increase in a firm's output decreases the other firms' price. As a result, an input that can be used to commit the firm to a higher output will reduce other firms' marginal profits, thus reducing competitors'

\footnotetext{
${ }^{13}$ In the department store example, strip retailing would appear to partially support this claim.
} 
output levels.

Oligopolistic competition between department stores can be motivated in the following way. In many cities, the size and capacity of the major department stores far exceed the other retail stores around them. Large retailers often sell a significant range of goods, competing with other firms along a range of taste parameters. When the branches of big retail firms are sufficiently larger than their niche competitors, we have a plausible case for oligopoly competition.

The strategic investment explanation of over-management requires strategic interaction between the firms. Such interactions can take place in an oligopolistic market. Therefore, our results will be applicable to industries where the oligopolistic model holds. Retail competition between department stores can fit into an oligopolistic setting. However, we should expect to see over-management occur more often in areas where department stores are the dominant retail firms. This limits the scope of applicability of our model. Nevertheless, many industries seem to satisfy the definition of oligopoly, implying that this requirement may not be too stringent.

Given the assumption of oligopolistic industry, we also need to discuss the issue of product differentiation, i.e. how substitutable the firms' products are. Each department store sells a variety of goods. The choice of products could itself be seen as a choice variable for the firm. However, this choice is made further up the chain of command, and so we will ignore it. For simplicity we will assume that each firm produces a homogeneous retail $\operatorname{good} x$.

To recap, when modeling over-management, we will focus on an oligopolistic industry producing a homogeneous good. The assumption of homogeneity is not essential, but the assumption of an oligopoly is. If the market did not fit into the oligopoly setting, then there would be no strategic benefits of management, and the strategic investment motive would not provide an explanation of over-management. 


\subsubsection{How are the firms' choice variables related to the struc- ture of the industry?}

\section{Bertrand or Cournot?}

The question of whether firms compete in prices or quantities can have important implications for the equilibrium outcome. Since Bertrand's 1883 criticism (Bertrand 1883) of Cournot's 1838 quantity game (Cournot 1897), economists have argued about the proper way to model competition. The controversy stems from the fact that most economists believe that firms compete by choosing prices, yet the equilibrium of a simple homogeneousgood price game is too extreme. In a Bertrand duopoly, two firms selling homogenous goods would reach the same equilibrium as with perfect competition (namely price equals marginal cost). In reality, however, firm behaviour resembles that of a Cournot oligopoly. This phenomenon is known as the Bertrand paradox.

Thus, we are left with a problem. Firms seem to follow the Bertrand approach in a sense that they compete by choosing prices, but the Cournot model yields outcomes that are closer to what we observe in reality (Cabral 2000). The literature offers three solutions to the Bertrand Paradox:

- Goods are imperfect substitutes, so firms can charge a markup on cost even if they compete in prices;

- Competition is repeated, so firms can collude and set prices higher than those in a static Bertand model (see Green \& Porter (1984), Fudenberg \& Tirole (1996), and Ivaldi, Jullien, Rey, Seabright \& Tirole (2003));

- Firms are capacity constrained, and so cannot produce the quantity which equalises price and marginal cost (see Brock \& Scheinkman (1985) and Dragan (n.d.)). 


\section{Strategic substitutes/complements}

In many settings, one firm's marginal payoff is decreasing in the other firms' output levels. ${ }^{14}$ That is, in quantity games output levels are strategic substitutes. The graphical interpretation is that the players' output reaction functions are downward sloping. If firms compete in prices instead, then their choice of management and workers would affect the prices they set. When firms compete in prices, usually one firm's marginal payoff is increasing in the other firms' prices. ${ }^{15}$ Thus, in Bertrand games prices are strategic complements.

Consider a game in strategic complements, i.e. in prices. If the firm can commit, it would set a price that is higher than the static Bertrand equilibrium. This will increase the marginal profit of their competitor. On the other hand, in games of strategic substitutes (i.e. quantity games) a firm would like to commit to a quantity above that of a static Cournot equilibrium. This will reduce the marginal profit of their competitor. Consequently, committable management would behave differently in these games. In particular, if the firm commits in a price game, we should observe "under-management". On the other hand, in a quantity game commitment would lead to "over-management". In this thesis, we assume that an increase in management will increase quantity and reduce price. Since the strategic properties of competition are rather important, they require further discussion.

\section{Flexibility and input choice}

Dixon (1986) elaborates on the essential differences between price and quantity competition. He states that the flexibility of a firms output choice is important in determining what model to use. Flexibility relates to the degree the firm can change an input in the very short run. He focuses on the choice of capital and labour inputs. In his model there are three possible input flexibility combinations during the production stage of a game; fixed capital and fixed labour, fixed capital but variable labour, and finally

\footnotetext{
${ }^{14}$ Matematically, if $\pi_{i}$ is the profit of a firm, $x_{i}$ is its quantity and $x_{j}$ is its competitors quantity, we have $\frac{\partial^{2} \pi_{i}}{\partial x_{i} x_{j}}<0$.

${ }^{15}$ Mathematically, if $\pi_{i}$ is the profit of a firm, $p_{i}$ is its price and $p_{j}$ is its competitors price, we have $\frac{\partial^{2} \pi_{i}}{\partial p_{i} p_{j}}>0$.
} 
variable capital and variable labour.

In Dixon's model, market demand is a function of price a la Bertrand. This implies that the output stage is competitive. When both inputs are variable, the standard Bertrand result applies. However, when both inputs are fixed, the output game becomes a game in capacities. It yields the Cournot equilibrium. Therefore, as long as the firm cannot adjust inputs quickly, a Cournot specification would be suitable.

In the case of department stores, we have a fixed level of capital stock, specifically checkouts. Except for management and workers, all inputs are determined exogenously.16 At the department store level, price competition occurs daily. However, the size of the worker input is constrained by a roster ${ }^{17}$, and, as previously stated, the managerial input takes even longer to adjust. Thus, when analysing the choice of the labour input in a department store on a week by week basis, a Cournot output game seems appropriate, as it is effectively setting the capacity in the daily price games.

\section{Worker input, flexibility and observability}

Our assumption that the worker input is adjustable allows us to treat it as un-committable. However, the above argument also implies that, at some time scale, it can be used for strategic commitment. The ability of the worker input to serve as a commitment instrument will depend on the adjustment cost of that input. However, "inflexibility" is only a necessary, not sufficient, condition for an input to be used for commitment. As we will discuss later, the worker input cannot be used for strategic investment because it is not observable.

\section{Adjustment costs, the short run, and the long run}

There is one further complication that has to be taken into consideration. Dixit (1997) discusses the adjustment cost of inputs in the short run and in the long run. By definition, the difference between the short run and the long run is in the flexibility of factors of production. In the short run,

\footnotetext{
${ }^{16}$ This comes from the fact that these decisions are made further up the vertical chain.

${ }^{17}$ This point will be important when discussing the adjustment cost of changing the worker input.
} 
some factors of production, such as capital, are fixed, while others, such as labour, are variable. However, in the long run both capital and labour are fully adjustable. According to Dixit, this distinction is not appropriate. In order to understand the choice of inputs, we need to study the costs associated with adjusting a given input. There is always some cost to changing an input. The big difference between capital and labour is the fact that the cost of adjusting capital (in the short run) is greater than the cost of adjusting labour.

We already argued that a firm's managerial input is harder to adjust than its worker input. In the context of the short versus the long run, this implies that the worker input is more likely to be adjusted in the short run than other less flexible inputs such as management. So in the two-stage model it is appropriate to view workers as adjustable in the short run, while management will be treated as unadjustable. Thus, when workers are chosen and output is determined, the managerial input is fixed. One consequence of this assumption is that the wage bill of managers becomes a fixed cost during the production stage.

Defining managerial and worker input choices in this way suffers from the same criticism that Dixit (1997) leveled at the short run to long run distinction between capital and labour. That is, it is unrealistic to assume that the worker input is costless to adjust at the start of the market stage, while the managerial input is infinitely costly to adjust at the start of the market stage. Nevertheless, this approach provides a starting point to analyse over-management. Our assumptions will be discussed in further detail in Chapter 4.

\section{Conclusion}

To summarise, this section we made the following assumptions:

- The output stage of the firm's game takes the form of Cournot competition.

- The managerial input is chosen before output is determined.

- To determine output, the firm must also choose its worker input. 


\subsection{Core Assumptions}

The preceding sections specified the assumptions that will be used in the strategic investment models. Some of these assumptions (e.g. the assumption of homogenous goods) were made for simplicity, and relaxing them should not qualitatively affect our results. These assumptions are peripheral.

However there are other assumptions (e.g. the assumption of oligopolistic industry), that are essential to our hypothesis. These are the core assumptions. In the first model of strategic investment, the core assumptions are as follows:

- Management and workers can be modeled as inputs.

- It is infinitely costly to change the level of managerial input at the start of the output stage.

- It is costless to change the level of worker input at the start of the output stage.

- A incremental increase in the managerial input increases the marginal product of the worker input ${ }^{18}$

- Firms can observe each others' choice of managerial input.

- Firms compete in an oligopolistic industry.

- Firms engage in Cournot competition (their quantities are strategic substitutes).

These assumptions are essential for over-management in the two-period setting. Relaxing some of them will require a substantial change of the model. The issues of information and timing in the game turn out to be important. Later in the thesis we will also discuss the cost of inputs, and how it is incorporated in the model.

\footnotetext{
${ }^{18}$ Note: we model this by assuming that management only influences production through supervision.
} 


\subsubsection{Grouping the Assumptions}

Our assumptions can be grouped in six categories. These categories yield a set of sufficient conditions for the result to hold in a two-stage model. They are:

1. That the managerial input positively influences the marginal product of other inputs. ${ }^{19}$

2. That the managerial input is an "irreversible investment", while other inputs are flexible.

3. That the managerial input is observable to other firms, but other inputs are not.

4. Firms operate in a duopolistic setting

5. Firms compete in quantities

Assumptions 4 and 5 are standard simplifying assumptions. They reflect profit maximisation, and the simplest version of Cournot, the Cournot duopoly ${ }^{20}$ Assumptions 1, 2 and 3 are common in the strategic investment literature. They are the extra conditions needed for our results. They involve assumptions about the nature of the managerial input ${ }^{21}$ The role of management in a given industry is an important determinant of whether it can be seen as a strategic investment resource. Therefore, the assumptions about the managerial input are very important for explaining overmanagement, and must be defended before any model can be analysed. Other elements of the model like the shape of market demand and costs will also be important. These will be described when we specify the model.

\footnotetext{
${ }^{19}$ Note: we use workers as a type of input that can be compared to management. However, managers may influence the marginal product of other inputs, as well.

${ }^{20}$ We discuss weakening the duopoly assumption in Appendix B.

${ }^{21}$ Note that we have not explicitly specified assumptions for the the worker input. This is because we follow the literature in assuming that adjustment of workers is costless and unobservable.
} 


\section{Chapter 3}

\section{Model One}

As discussed earlier, the firm's choice of labour is often viewed differently to the choice of other factors of production. When studying labour inputs, there is often a focus on the provision of incentives within a principalagent relationship. Papers by Jensen \& Meckling (1976) and Holstrom \& Milgrom (1991) have shown that such relationships are important for relating the labour input of a firm to their choice of output. We aim to show a separate but equally important characteristic of the labour input: its commitment value.

\subsection{Commitment value of management}

Papers by Spence (1977) and Brander \& Spencer (1983) found that strategic commitment can influence firm decisions such as capital investment and research and development. In these papers, the core assumptions that generate the commitment value of a given input are listed below.

- The irreversibility of the input

- The observability of the input by other firms

- The input must shift the reaction function of the firm

If we decompose the labour input into managerial and worker types, the conditions for management to behave as a committable resource will be as 
follows.

- Management is viewed as fixed when the other inputs are chosen

- The management input must be observed by other firms

- The management input must be able to influence the level of output

Exactly how this process works will be shown by way of a mathematical model. But first it is important to relate the conditions of Brander \& Spencer (1983) to the three conditions stated above.

\subsubsection{Irreversibility}

The argument that the management input is fixed stems from its irreversibility. Irreversibility of management can be observed clearly in a department store, where both managers and workers are used as inputs. We assume that the appropriate time period for a stage in this analysis is one month. ${ }^{1}$ For an input to be fixed during a period of time, we require both the extensive and the intensive margins to remain unchanged. As mentioned in chapter 2 , in the context of a given firm, the extensive margin refers to the number of employees. The intensive margin then refers to the hours that each employee contributes. For the extensive margin to be fixed, the firm should not be able to remove or hire employees. For the intensive margin to be fixed, the firm should not be able to change the number of hours that employees work.

In the case of the managerial input, both margins are fixed. The extensive margin is fixed as it is impossible to remove managers and difficult to add them over the relevant time period. This is due to the contractual difficulties of removing current managers and the cost of training new ones. The intensive margin is fixed as the management staff are on salaries which pay them for a set number of worked hours. Since both margins are fixed, the managerial input cannot be changed during this time frame. Therefore, management can be viewed as irreversible.

\footnotetext{
${ }^{1}$ If a manager decides to leave the job/training programme, he has to give a one month's notice.
} 
The argument for irreversibility of management can be summarised as follows.

1. The extensive margin of management is fixed at the time of the firms' choice of output;

2. the intensive margin of management is fixed at the time of the firms' choice of output. Therefore,

3. management is irreversible at the time of the firms' choice of output.

Conversely, the worker input is not a fixed resource during a given month. At the extensive margin, workers are cheap to remove and replace. It is also relatively simple for firms to hire additional workers in a short time frame if they want to increase production. At the intensive margin, workers are paid an hourly wage, and work according to an adjustable weekly roster. This allows some flexibility in changing the worker input from week to week. As a result, the worker input is flexible over the relevant time period.

Department store competition can thus can be modeled as a game where the worker input is chosen repeatedly (say weekly) over the month, while the managerial input is fixed up-front. The irreversibility assumption is stronger than the previous chapter's argument that management is costly to adjust. This will become an important issue when discussing the results of the model.

\subsubsection{Observability}

In addition to being irreversible, management must be observed by all players. Otherwise it will not influence the choices of other firms. Observability is presumed to come from the irreversible nature of the managerial resource. As argued, the intensive and extensive margins of management cannot be changed. Thus, if the firm's opponents observe this input in one period, they will have observed its value over the entire game. In this thesis, we assume that firms are able to observe the number of managers hired by their competitors at the start of the game. ${ }^{2}$

\footnotetext{
${ }^{2}$ Our approach is similar to that of the strategic investment literature, which postulates that the capital stock of a given firm can be observed by all players.
} 
The argument for observability of the managerial input can be summarised as follows.

1. Management is irreversible when firms choose output.

2. Competitors can easily verify the number of managers a firm has at the start of a game.

3. The number of hours a manager works are fixed, and known by other firms. Therefore,

4. Management is observable when the firm chooses its output level.

The combination of irreversibility and observability justifies the use of a sequential model of labour input choice in which the managerial input is set first, and the worker input is set second.

\subsubsection{The effect of management on output}

In the following models, we also have to specify how management influences the choice of worker input and output levels.

In our department store example, we will assume that quantities are strategic substitutes. That is, an increase in a firm's output level reduces the opponent's marginal profit. The combination of strategic substitutability, irreversibility, and observability provides a setting where strategic commitment can play an important role. Papers by Spence (1977) and Brander \& Spencer (1983) show that, in a game where quantities are strategic substitutes, strategic considerations may lead to an excessive use of the commitment resource. If the managerial input can be used for strategic commitment, then this will deliver a potential explanation of over-management.

Given strategic substitutability of output levels, we show that complementarity of labour inputs is a sufficient condition for over-management. This complementarity implies that the choice of the unobservable resource will not be made in a way that completely offsets or reverses the impact of the observable factor of production. This will allow firms to use the managerial input as an effective commitment device. 


\subsection{Summary argument}

Our earlier discussion led to the following argument.

1. Management influences the final level of output;

2. management is irreversible when the firms choose output;

3. management is observable when the firms choose output. Therefore,

4. management can be used for strategic commitment (from (1), (2) and (3)).

The model below aims to illustrate the logical link between premises 1, 2, and 3 and our conclusion, 4 .

\subsection{General setting}

Suppose that there are two firms, $A$ and $B$, that engage in quantity competition. Each player uses two inputs: management and workers. Firm $A$ 's management and workers are denoted by $M$ and $L$ respectively, while firm $B^{\prime}$ s management and workers are denoted by $\tilde{M}$ and $\tilde{L}$. Given the available technology, these input bundles will determine the firms' output levels. Let $A^{\prime}$ s production function be $x=f(L, M)$ and $B^{\prime}$ s production function be $\tilde{x}=\tilde{f}(\tilde{L}, \tilde{M})$.

The prices that firms $A$ and $B$ face are determined by the inverse demand functions $P(x, \tilde{x})$ and $\tilde{P}(\tilde{x}, x)$. We also assume linear input costs, $r M+w L$ and $r \tilde{M}+w \tilde{L}$, respectively, where $r$ is the wage of a manager and $w$ is the wage of a worker. Since $r$ and $w$ are prices, we will assume that $r>0, w>$ 0 .

Given the production functions of $A$ and $B$, the payoff functions of these firms take the form

$$
\begin{aligned}
& \pi(L, M, \tilde{L}, \tilde{M})=P(f(L, M), \tilde{f}(\tilde{L}, \tilde{M})) f(L, M)-r M-w L \\
& \tilde{\pi}(\tilde{L}, \tilde{M}, L, M)=\tilde{P}(\tilde{f}(\tilde{L}, \tilde{M}), f(L, M)) \tilde{f}(\tilde{L}, \tilde{M})-r \tilde{M}-w \tilde{L}
\end{aligned}
$$


For notational simplicity, we define the revenue functions in the following way:

$$
\begin{aligned}
& R(x, \tilde{x})=P(x, \tilde{x}) x \\
& \tilde{R}(\tilde{x}, x)=\tilde{P}(\tilde{x}, x) \tilde{x} .
\end{aligned}
$$

We use a subscript $i$ to denote the partial derivative of a function with respect to its $i$-th argument. For example, the expression $R_{1}(x, \tilde{x})$ is defined as $\partial R / \partial x$. Similarly, two subscripts denote second-order derivatives. Assume that $R, \tilde{R}$ satisfy:

$$
R_{1,2}<0, \tilde{R}_{1,2}<0, R_{1,1}<0, R_{2,2}<0, \tilde{R}_{1,1}<0, \tilde{R}_{2,2}<0 .
$$

Thus, we can write profits as

$$
\begin{aligned}
& \pi(L, M, \tilde{L}, \tilde{M})=R(f(L, M), \tilde{f}(\tilde{L}, \tilde{M}))-w L-r M \\
& \tilde{\pi}(\tilde{L}, \tilde{M}, L, M)=\tilde{R}(\tilde{f}(\tilde{L}, \tilde{M}), f(L, M))-w \tilde{L}-r \tilde{M}
\end{aligned}
$$

Firms choose their inputs to maximise these payoff functions. For brevity sometimes we will suppress the arguments of the revenue functions:

$$
\begin{aligned}
& \pi=R-r M-w L \\
& \tilde{\pi}=\tilde{R}-w \tilde{L}-r \tilde{M} .
\end{aligned}
$$

\subsection{Cost minimising input bundles}

It is useful to compare the choice of inputs that arise in oligopolistic competition to the input bundle that minimises the cost of producing the equilibrium output levels. Costs are minimised if, for a given level of output, inputs are chosen to produce that output at the least cost.

Consider the cost minimisation problem of firm $A$. Its goal is to minimise the input cost $C=w L+r M$ while producing at least some target level 
of output $x^{*}=f(L, M)$. Assume an interior solution. The corresponding Lagrangian is:

$$
€(L, M, \lambda)=w L+r M+\lambda\left(x^{*}-f(L, M)\right)
$$

Differentiating with respect to $L, M$ and $\lambda$ yields the following first-order conditions:

$$
\begin{gathered}
\mathrm{Ł}_{1}=w-\lambda f_{1}=0 \Longleftrightarrow w=\lambda f_{1} \\
\mathrm{Ł}_{2}=r-\lambda f_{2}=0 \Longleftrightarrow r=\lambda f_{2} \\
\succeq_{3}=x^{*}-f(L, M)=0 .
\end{gathered}
$$

Dividing the first-order conditions for $L$ and $M$ gives us:

$$
\frac{w}{r}=\frac{f_{1}}{f_{2}} .
$$

This necessary condition states that the ratio of worker to manager wages must be equal to the marginal rate of technical substitution between these two inputs.

\subsection{Static competition}

Our first model is a one-shot game in which firms choose all their labour inputs simultaneously. It provides a benchmark for comparison with the sequential model considered later in this chapter. In the simultaneousmove game, the opponent's managerial input is not observable, and so neither firm has information about the other firm's choices. Without observability, the managerial input has no commitment value.

In an interior equilibrium, we can characterise firm $A^{\prime}$ s optimal choice of inputs by taking the first-order conditions with respect to $L$ and $M$. The derivatives of firm $A$ 's payoff function are: 


$$
\begin{aligned}
& \pi_{1}=R_{1} f_{1}-w \\
& \pi_{2}=R_{1} f_{2}-r
\end{aligned}
$$

We can obtain similar expressions for firm $B$. We will refer to these derivatives as the marginal profits of the inputs. Setting the marginal profit of each input to zero delivers first-order conditions for the profit-maximizing input choices. The ratio of these first-order conditions is:

$$
\frac{R_{1} f_{1}}{R_{1} f_{2}}=\frac{w}{r}
$$

It simplifies to:

$$
\frac{f_{1}}{f_{2}}=\frac{w}{r}
$$

This condition must hold in any Nash equilibrium where firms simultaneously choose inputs to maximise profits. It is the same as the necessary condition we obtained for the cost minimisation problem. For a fixed level of output $x$, there is only one input bundle that can satisfy this ratio, provided that the marginal products are decreasing in the level of the respective input. Therefore, equilibrium output will be produced using the cost-minimising input bundles. This establishes the duality between cost minimisation and profit maximisation in the simultaneous-move game. As long as inputs are chosen in an unobservable or fully reversible way, the two problems have the same solution.

However, this static model is not a realistic representation of competition involving branch level managers. As we will show, a more plausible setting will generate the result of over-management. The purpose of the above model was to provide a benchmark which helps us define the idea of over-management. 


\subsection{Unilateral commitment}

\subsubsection{Motivation}

The benchmark model did not take into account the irreversible and observable nature of the managerial input. Thus, it ignored the role of management as a committable resource. The first step in illustrating how irreversibility and observability of management can change firm behaviour is to analyse the case when only one firm chooses its management up front. In other words, only one firm will be able to use management as a commitment instrument.

The purpose of this exercise is two-fold. By illustrating how a single firm's actions change when its management input is observable and irreversible, we can study the difference that these attributes make. Furthermore, by comparing the payoff of the committed firm to the payoff this firm receives without committing, we can determine whether the firm gains an advantage by choosing to commit.

Our analysis relates to the idea of flexibility in Dixon (1986). Dixon "endogenises" the firm's choice of labour flexibility by comparing the equilibria in a number of games with varying rigidity. It is important to note that our notion of flexibility differs from the concept used in real options analysis. In that literature, firms value flexibility(Dixit \& Pindyck 1995) because it gives them room to adjust when the elements of the mode $]^{3}$ are stochastic. Therefore, in such models flexibility has value.

In this thesis, flexibility is detrimental to the players. If a firm could undo its former choices during the competition stage, then it cannot commit to an action that may prevent entry, or increase profits. When strategic considerations enter the decision process of the firm, self-interest can be its worst enemy. Later chapters will underscore the importance of this idea.

${ }^{3}$ e.g. demand for the product 


\subsubsection{Commitment as a choice}

The choice to commit is a theoretical device used to explain why the game may be such that players are able to commit. Fundamentally, the firm could set up the game in a way which allows it to commit. In such a setting, the structure of the game itself becomes endogenous, as firms can invest in creating the type of game they play.

There are three situations in which a firm may have an incentive to invest in creating commitment opportunities:

1. Managerial input cannot be adjusted; here the firm will allow their managerial input to be observed by other firms at no cost.

2. Managerial input is observable, so firms design contracts which make the managerial input ex post irreversible.

3. Managerial input is neither observable or irreversible, however it is cheaper to invest in making the managerial input observable and irreversible than doing so with other inputs.

If profits from committing exceed those from not committing, firms may end up playing a prisoners' dilemma. Consider the following symmetric game. 
Firm J

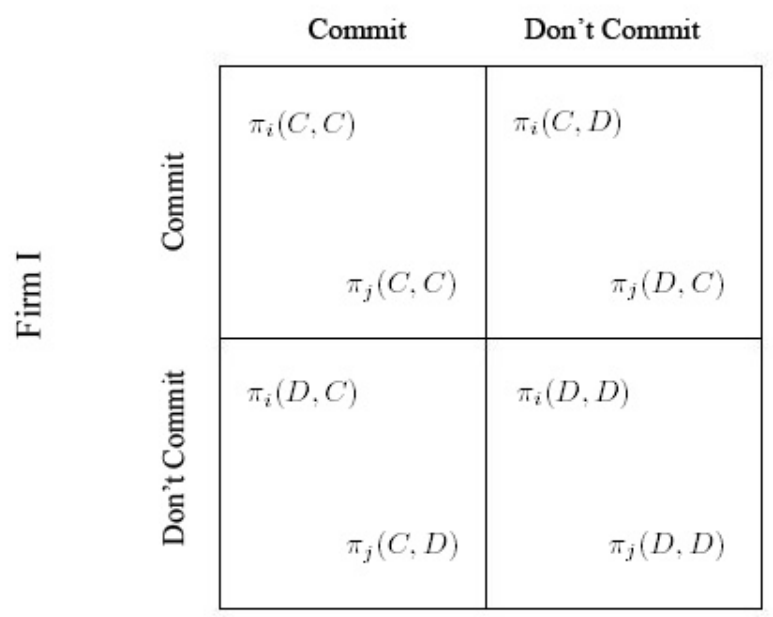

Suppose that if only one firm can commit, that firm gets a payoff of $\pi(C, D)$. Let $\pi(D, D)$ be the payoff each firm obtains in the benchmark simultaneousmove game considered earlier. Assume that $\pi(C, C)>\pi(D, C)$ and $\pi(C, D)>$ $\pi(D, D)$. Then committing would be a dominant strategy: it will bring a higher payoff no matter what the other firm is doing.

If $\pi(D, D)>\pi(C, C)$, we will have a game where firms are jointly made worse off by their commitment. That game would be a prisoner's dilemma in terms of the choice of whether to commit or not. This is an important consideration to keep in mind when we discuss the "horizon" of the game in chapter 4 .

In the sequential move game, we will show that a firm would prefer to commit if the other firm is committing. In other words, commitment is profitable. As a result of this, firms will have an incentive to make the managerial input irreversible or observable in the three ways mentioned above.

\subsubsection{The unilateral commitment game}

In the benchmark case, we assumed that all inputs were chosen at the same time. This assumption was not critical, since input choices were unobserv- 
able. However, when studying commitment, timing becomes a crucial element of the game. In our next model, firms' choices will be made in the following order:

Stage 1: Firm $A$ chooses their level of managerial input, $M$.

Stage 2: Both firms observe the value of $M$. Then firm $A$ chooses their worker input $L$, and firm $B$ chooses their managerial and worker inputs, $\tilde{M}$ and $\tilde{L}$, respectively.

To find the subgame-perfect Nash equilibrium of this game, we use backward induction. First, we solve for the stage-two game equilibrium inputs, $L, \tilde{M}$ and $\tilde{L}$, while holding $M$ fixed. This allows us to write these labour inputs as functions of $M$. Substituting these functions into firm $A$ 's stageone problem, we can solve for firm $A^{\prime}$ s subgame-perfect choice of $M$. The value of $M$ can then be inserted into the functions for $L, \tilde{M}$ and $\tilde{L}$ to deliver their subgame-perfect equilibrium values.

\section{Stage 2}

Starting from stage two, we first compute the derivative of firm $A^{\prime}$ s profit with respect to $L$, as well as the derivatives of firm $B^{\prime}$ s profit with respect to $\tilde{M}$ and $\tilde{L}$. When these derivatives are set equal to zero, they deliver first-order conditions that determine the optimal choices of $L, \tilde{M}$ and $\tilde{L}$ for a given level of management $M$ :

$$
\begin{aligned}
& \pi_{1}=R_{1} f_{1}-w=0 \\
& \tilde{\pi}_{1}=\tilde{R}_{1} \tilde{f}_{1}-\tilde{w}=0 \\
& \tilde{\pi}_{2}=\tilde{R}_{1} \tilde{f}_{2}-\tilde{r}=0
\end{aligned}
$$

Note that if the value of $M$ was the same as in the benchmark case, these first-order conditions would yield equilibrium values for the other inputs that are the same as in the simultaneous-move game. However, since $M$ is used for strategic commitment, its subgame-perfect equilibrium value will be different. 


\section{Stage 1}

The above first-order conditions define the stage-two equilibrium inputs $L, \tilde{M}$ and $\tilde{L}$ as functions of $M$. Let these functions be $L^{*}(M), \tilde{L}^{*}(M)$ and $\tilde{M}^{*}(M)$. Since $A$ correctly infers how its choice of management affects $B^{\prime}$ s stage-2 choice of inputs, these functions must be substituted into firm $A^{\prime}$ s stage- 1 objective. Thus, in the first stage, $A^{\prime}$ 's payoff function takes the form:

$$
\pi^{*}(M)=R\left(f\left(L^{*}(M), M\right), \tilde{f}\left(\tilde{L}^{*}(M), \tilde{M}^{*}(M)\right)\right)-w L^{*}(M)-r M
$$

Firm $A^{\prime}$ s optimal choice of $M$ in that stage is then determined by the firstorder condition $\pi_{2}^{*}=0$. Differentiating $A^{\prime}$ s profit function and applying the envelope theorem, we obtain:

$$
\frac{\partial \pi^{*}}{\partial M}=R_{1} f_{2}+R_{2}\left(\tilde{f}_{1} \tilde{L}_{1}+\tilde{f}_{2} \tilde{M}_{1}\right)-r
$$

\section{Implications for stage-1 management}

Recall our assumption that the marginal product of labour inputs is decreasing. It implies that if $\partial \pi^{*} / \partial M$ is positive for the value of $M$ that solves $\partial \pi / \partial M=0$, then the subgame-perfect equilibrium choice of $M$ in the unilateral commitment game will be higher. The verbal argument is as follows. Since the production function is concave in inputs, the marginal profit of management is monotonically decreasing in $M$. Thus, if $\partial \pi^{*} / \partial M>$ 0 when $\partial \pi / \partial M=0$, then the first-order condition $\partial \pi^{*} / \partial M=0$ will be satisfied for a higher value of $M$. Consequently, the subgame-perfect management must be higher than that in the simultaneous-move game.

To complete our argument, we need to establish that $\left(\frac{\partial \pi^{*}}{\partial M}-\frac{\partial \pi}{\partial M}\right)>0$. Consider the value of $M$ which solves $\partial \pi / \partial M=0$. For that value, we have:

$$
\frac{\partial \pi^{*}}{\partial M}-\frac{\partial \pi}{\partial M}=R_{2}\left(\tilde{f}_{1} \tilde{L}_{1}+\tilde{f}_{2} \tilde{M}_{2}\right)
$$

We assumed that firm $A^{\prime}$ 's revenue is decreasing in $B^{\prime}$ s output: $R_{2}<0$. Thus, a sufficient condition for expression (6) to be positive is that $\tilde{L}_{1}<0$ 
and $\tilde{M}_{1}<0$. In other words, we have to show that the firms' management levels are strategic substitutes, and that firm $B^{\prime}$ s worker input and firm $A^{\prime}$ s managerial input are strategic substitutes. Since $\tilde{L}^{*}$ is implicitly defined by the first-order condition $\tilde{\pi}_{1}=0$, the effect of $M$ on $\tilde{L}^{*}$ will depend on how $M$ affects $B^{\prime}$ 's marginal profit $\tilde{\pi}_{1}$. In particular, if $\tilde{\pi}_{1,2}<0$, then $\tilde{L}_{1}<04$. A symmetric argument holds for $\tilde{M}$.

One way to solve the problem is to explicitly derive the slopes $L_{1}, \tilde{L}_{1}$, and $\tilde{M}_{1}$ of the three functions. These functions are defined by three stage- 2 first-order conditions $\pi_{1}=0, \tilde{\pi}_{1}=0, \tilde{\pi}_{2}=0$. Therefore, we can obtain $L_{1}$, $\tilde{L}_{1}$, and $\tilde{M}_{1}$ by differentiating these first-order conditions with respect to $M$.

\section{Alternative representation}

To simplify the analysis, we now explore an alternative formulation of the unilateral commitment game. It is convenient to study an equivalent game where, in stage 2 , firm $B$ competes by choosing its output $\tilde{q}$ rather than the labour inputs $\tilde{L}$ and $\tilde{M}$. This new game reduces the dimension of firm $B^{\prime}$ s strategy space, which allows us to use standard techniques from the strategic investment literature.

Suppose that, in stage 2, firms $A$ and $B$ choose $L$ and $\tilde{q}$, respectively, to maximise

$$
\psi(L, M, \tilde{q})=R(f(M, L), \tilde{q})-r M-w L
$$

and

$$
\tilde{\psi}(\tilde{q}, L, M)=\tilde{R}(\tilde{q}, f(L, M))-\tilde{C}(\tilde{q})
$$

where $\tilde{C}(\tilde{q})$ is firm $B^{\prime}$ s cost as a function of output..$^{5}$ Just as before, the stage-2 Nash equilibrium defines $\tilde{q}$ and $L$ as functions of $M$. Let these functions be $\tilde{q}^{*}(M)$ and $L^{*}(M)$. In stage 1 , firm $A$ would choose management to maximise its stage-two equilibrium profit

\footnotetext{
${ }^{4}$ As $M$ reduces the marginal profit of $\tilde{L}$, implying that a lower value of $\tilde{L}^{*}$ is now optimal

${ }^{5}$ The cost function is obtained from firm $B$ 's cost minimization problem.
} 


$$
\psi^{*}(M)=R\left(f\left(M, L^{*}(M)\right), \tilde{q}^{*}(M)\right)-r M-w L^{*}(M) .
$$

Since this game is equivalent to the unilateral commitment game considered earlier, it must be true that

$$
\tilde{q}^{*}(M) \equiv \tilde{f}\left(\tilde{L}^{*}(M), \tilde{M}^{*}(M)\right)
$$

The stage-2 first-order conditions are:

$$
\left.R_{1}\left(f\left(L^{*}(M), M\right), \tilde{q}^{*}(M)\right) f_{1}\left(L^{*}(M), M\right)\right)-w=0
$$

and

$$
\tilde{R}_{1}\left(\tilde{q}^{*}(M), f\left(L^{*}(M), M\right)\right)-\tilde{C}\left(\tilde{q}^{*}(M)\right)=0 .
$$

Applying the implicit function theorem to these first-order conditions allows us to identify the derivatives $L_{1}^{*}$ and $\tilde{q}_{1}^{*}$.

$$
\begin{gathered}
L_{1}^{*}=-\frac{\left(R_{1,1} f_{1} f_{2}+R_{1,2} f_{1} \tilde{q}_{1}^{*}+R_{1} f_{1,2}\right)}{\left(R_{1,1} f_{1} f_{1}+R_{1} f_{1,1}\right)} \\
\tilde{q}_{1}^{*}=-\frac{\tilde{R}_{1,2}\left(f_{1} L_{1}^{*}+f_{2}\right)}{\left(\tilde{R}_{1,1}-\tilde{C}_{1,1}\right)}
\end{gathered}
$$

Solving these equations simultaneously for $\tilde{q}_{1}^{*}$ delivers

$$
\tilde{q}_{1}^{*}=-\frac{\left(R_{1,1} f_{1} f_{1}+R_{1} f_{1,1}\right) \tilde{R}_{1,2} f_{2}-\left(R_{1,1} f_{1} f_{2}+R_{1} f_{1,2}\right) \tilde{R}_{1,2} f_{1}}{\left(R_{1,1} f_{1} f_{1}+R_{1} f_{1,1}\right)\left(\tilde{R}_{1,1}-\tilde{C}_{1,1}\right)-R_{1,2} f_{1} \tilde{R}_{1,2} f_{1}} .
$$

Stability of the stage-2 game Nash equilibrium requires that the denominator of the above expression is positive ${ }^{6}$ The assumption that $R_{1,2}<0$ implies that the sign of $\tilde{q}_{1}^{*}$ is equal to the sign of the numerator $\left(R_{1,1} f_{1} f_{1}+\right.$ $\left.R_{1} f_{1,1}\right) f_{2}-\left(R_{1,1} f_{1} f_{2}+R_{1} f_{1,2}\right) f_{1}$. In other words, for our result we require

\footnotetext{
${ }^{6}$ See the discussion of the Routh-Hurwicz condition below.
} 
that the impact of the worker input on the marginal profit of workers exceeds the impact of the management input on the marginal profit of workers. As long as this condition is satisfied, an increase in the managerial input will reduce the other firm's output.

We can provide an alternative interpretation of this condition. Note that the sign of $\tilde{q}_{1}^{*}$ must be equal to the sign of $R_{1}\left(f_{1,1} f_{2}-f_{1,2} f_{1}\right)$. We know that $\left(f_{1,1} f_{2}-f_{1,2} f_{1}\right)$ will be positive as long as $L$ is a "normal input". The worker input is called normal if, for a higher output level, the cost minimising bundle involves more of that input. Mathematically, $L$ is a normal input if the marginal rate of technical substitution $\left(-\frac{f_{2}}{f_{1}}\right)$ is decreasing in $L$. Differentiating the MRTS with respect to $L$ yields $\left(f_{1,1} f_{2}-f_{1,2} f_{1}\right) /\left(f_{1}\right)^{2}$. Therefore, a decreasing MRTS would require that $f_{1,1} f_{2}-f_{1,2} f_{1}>0$, which in turn implies that our result will hold.

A sufficient condition for $\tilde{q}_{1}^{*}<0$ is that there is complementarity between the two inputs: $f_{1,2} \geqslant 0.7$ Even when the production function is additively separable in inputs (i.e. $f_{1,2}=0$ ), the expression will have the required sign as long as $f_{1,1}<0$.

\subsubsection{Over-management}

Having established that $\tilde{q}_{1}^{*}<0$, we now explore whether the subgameperfect equilibrium exhibits over-management.

For a given level of output, the cost minimising bundle is determined by the condition

$$
\frac{f_{1}}{f_{2}}=\frac{w}{r}
$$

In the unilateral commitment game, firm $A^{\prime}$ s profit maximising choice of inputs satisfies

$$
\frac{R_{1} f_{1}}{R_{1} f_{2}+R_{2} \tilde{q}_{1}^{*}}=\frac{w}{r} .
$$

\footnotetext{
${ }^{7}$ In chapter 2, we justified this assumption by appealing to the hierarchy literature
} 
If this input bundle satisfies the cost minimisation condition, it will violate the equilibrium condition of the game. Since $\tilde{q}_{1}^{*}<0$, the left hand side (the ratio of the marginal revenue products) will be less than the right hand side (the ratio of the marginal costs). To achieve equality, we would need to either increase the numerator (the marginal revenue product of the worker input), decrease the denominator (the marginal revenue product of the managerial input), or both. Given our assumption that the marginal revenue product of both inputs falls as the amount of the input rises, this can be accomplished by decreasing $L$ or increasing $M^{8}$ Thus, in equilibrium the firm will choose a more "manager intensive" combination of inputs relative to the cost minimising bundle. In other words, we will observe over-management.

\subsection{Bilateral commitment}

So far we have motivated why one firm may want to implement overmanagement. However, if one firm has the incentive to hire excess managers, then its competitors may also have a similar incentive. To analyse the case where multiple firms commit to management, we study a duopoly game in which both firms choose their managers up-front.

The stages of the bilateral commitment game are as follows:

Stage 1: Both firms choose their levels of managerial inputs, $M$ and $\tilde{M}$, simultaneously.

Stage 2: The firms observe the values of $M$ and $\tilde{M}$. Given management levels, they then choose their worker inputs. Once $L$ and $\tilde{L}$ have been chosen, the output levels are determined and sold on the market.

Again, we characterise the subgame-perfect equilibrium of this game using backward induction.

\footnotetext{
${ }^{8}$ Assuming that the impact of $M$ on the marginal revenue product of management exceeds the impact of $M$ on the marginal revenue product of the worker input
} 


\subsubsection{Stage 2}

Differentiating the payoff functions with respect to the firm's choice of worker input yields the following stage two first-order conditions:

$$
\begin{aligned}
& \pi_{1}=R_{1} f_{1}-w=0 \\
& \tilde{\pi}_{1}=\tilde{R}_{1} \tilde{f}_{1}-w=0
\end{aligned}
$$

They would be identical to the first-order conditions of the simultaneousmove game if each firm chose the same level of managerial input as it did in the static benchmark.

The stage-2 equilibrium choice of worker input is consistent with shortrun cost minimisation. During that stage, expenditure on management is a fixed cost. In the short run (stage two), the variable cost is driven entirely by the worker input. When there is a single input, cost minimisation simply involves choosing the input that can produce the target level of output.

\subsubsection{Stage 1}

The first-order conditions for $L$ and $\tilde{L}$ define the stage-two equilibrium worker inputs as functions of management. Let these functions be $L^{* *}(M, \tilde{M})$ and $\tilde{L}^{* *}(M, M)$. We will use them to determine the choice of management in stage 1 . After substituting $L^{* *}$ and $\tilde{L}^{* *}$, the payoff functions of firms $A$ and $B$ take the form:

$$
\begin{aligned}
& \pi^{* *}(M, \tilde{M})=R(f(L(M, \tilde{M}), M), \tilde{f}(\tilde{L}(\tilde{M}, M), \tilde{M}))-w L(M, \tilde{M})-r M \\
& \tilde{\pi}^{* *}(\tilde{M}, M)=R(\tilde{f}(\tilde{L}(\tilde{M}, M), \tilde{M}), f(L(M, \tilde{M}), M))-w \tilde{L}(\tilde{M}, M)-r \tilde{M}
\end{aligned}
$$

In stage 1, firms choose their management inputs to maximise $\pi^{* *}(M, \tilde{M})$ and $\tilde{\pi}^{* *}(\tilde{M}, M)$, respectively. Differentiating $\pi^{* *}(M, \tilde{M})$ with respect to $M$ yields the first-order condition: 


$$
\frac{\partial \pi^{* *}}{\partial M}=R_{1}\left(f_{1} L_{1}^{* *}+f_{2}\right)+R_{2}\left(\tilde{f}_{1} \tilde{L}_{2}^{* *}\right)-w L_{1}-r=0
$$

Similarly, for firm $B$ we get

$$
\frac{\partial \tilde{\pi}^{* *}}{\partial \tilde{M}}=\tilde{R}_{1}\left(\tilde{f}_{1} \tilde{L}_{1}^{* *}+\tilde{f}_{2}\right)+\tilde{R}_{2}\left(f_{1} L_{2}^{* *}\right)-\tilde{w} \tilde{L}_{1}^{* *}-\tilde{r}=0
$$

Equations 3.9 and 3.10 take into account that managerial inputs will have an impact on both the firm's own choice of workers (through $L_{1}^{* *}$ and $\tilde{L}_{1}^{* *}$, respectively) and on the opponent's choice of workers (through $L_{2}^{* *}$ and $\tilde{L}_{2}^{* *}$, respectively).

\subsubsection{Comparison with the simultaneous-move game}

A comparison of these first-order conditions to those from the simultaneousmove game yields a difference of $R_{2} \tilde{f}_{1} \tilde{L}_{2}^{* *}$. The marginal profit in the simultaneous-move game will be equal to that in the sequential-move game when, for fixed managerial inputs, this difference term vanishes:

$$
R_{2} \tilde{f}_{1} \tilde{L}_{2}^{* *}=0 .
$$

If $R_{2} \tilde{f}_{1} \tilde{L}_{2}^{* *}>0$, management will be higher in the bilateral commitment game. To see that, let us fix management at the static benchmark levels. Then its marginal revenue in the bilateral commitment game will exceed its marginal cost. This implies that it is optimal to increase management. ${ }^{9}$ Given our assumption that $R_{2}<0$, we therefore have to show that $\tilde{L}_{2}^{* *}<$ 0 . In other words, firm $B$ 's optimal worker input must be decreasing in $A$ 's managerial input. Note that this does not necessarily follow from the strategic substitutability of output levels. It is possible that committing to a higher value of $M$ may cause an even bigger decrease in $L$, so that the overall effect is a fall in production. In that case, an increase in $M$ will actually increase the marginal revenue (and hence the marginal profit) of firm $B$. This, in turn, will result in $B$ choosing a higher level of $\tilde{L}$.

The stage-2 equilibrium choices or worker inputs are implicitly defined by the first-order conditions $\frac{\partial \pi}{\partial L}=0$ and $\frac{\partial \tilde{\pi}}{\partial \tilde{L}}=0$. Thus, we can apply the

\footnotetext{
${ }^{9}$ Assuming diminishing marginal products of the two inputs.
} 
implicit function theorem to find the slopes $L_{1}^{* *}, L_{2}^{* *}, \tilde{L}_{1}^{* *}, \tilde{L}_{2}^{* *}$ of the firms' strategies. Differentiating these first-order conditions gives us:

$$
\begin{aligned}
& \frac{\partial^{2} \pi}{\partial L \partial \tilde{M}}=R_{1,1} f_{1} f_{1} L_{2}^{* *}+R_{1,2} f_{1}\left(\tilde{f}_{1} \tilde{L}_{1}^{* *}+\tilde{f}_{2}\right)+R_{1} f_{1,1} L_{2}^{* *}=0 \\
& \frac{\partial^{2} \pi}{\partial L \partial M}=R_{1,1} f_{1}\left(f_{1} L_{1}^{* *}+f_{2}\right)+R_{1,2} f_{1} \tilde{f}_{1} \tilde{L}_{2}^{* *}+R_{1}\left(f_{1,1} L_{1}^{* *}+f_{1,2}\right)=0 \\
& \frac{\partial^{2} \tilde{\pi}}{\partial \tilde{L} \partial M}=\tilde{R}_{1,1} \tilde{f}_{1} \tilde{f}_{1} \tilde{L}_{2}^{* *}+\tilde{R}_{1,2} \tilde{f}_{1}\left(f_{1} L_{1}^{* *}+f_{2}\right)+\tilde{R}_{1} \tilde{f}_{1,1} \tilde{L}_{2}^{* *}=0 \\
& \frac{\partial^{2} \tilde{\pi}}{\partial \tilde{L} \partial \tilde{M}}=\tilde{R}_{1,1} \tilde{f}_{1}\left(\tilde{f}_{1} \tilde{L}_{1}^{* *}+\tilde{f}_{2}\right)+\tilde{R}_{1,2} \tilde{f}_{1} f_{1} L_{2}^{* *}+\tilde{R}_{1}\left(\tilde{f}_{1,1} \tilde{L}_{1}^{* *}+\tilde{f}_{1,2}\right)=0
\end{aligned}
$$

This system of equations has four unknowns: $L_{1}^{* *}, L_{2}^{* *}, \tilde{L}_{1}^{* *}, \tilde{L}_{2}^{* *}$. Solving for $\tilde{L}_{2}^{* *}$ yields:

$$
\tilde{L}_{2}^{* *}=-\frac{\tilde{R}_{1,2} \tilde{f}_{1}\left[f_{2}\left(R_{1,1} f_{1} f_{1}+R_{1} f_{1,1}\right)-f_{1}\left(R_{1,1} f_{1} f_{2}+R_{1} f_{1,2}\right)\right]}{\left(R_{1,1} f_{1} f_{1}+R_{1} f_{1,1}\right)\left(\tilde{R}_{1,1} \tilde{f}_{1} \tilde{f}_{1}+\tilde{R}_{1} \tilde{f}_{1,1}\right)-R_{1,2} f_{1} \tilde{f}_{1} \tilde{R}_{1,2} f_{1} \tilde{f}_{1}} .
$$

Again, dynamic stability of the stage-2 game requires that the denominator of this expression is positive. Note that the denominator is in fact

$$
\frac{\partial^{2} \pi}{\partial x^{2}} \frac{\partial^{2} \tilde{\pi}}{\partial \tilde{x}^{2}}-\frac{\partial^{2} \pi}{\partial \tilde{x} \partial x} \frac{\partial^{2} \tilde{\pi}}{\partial x \partial \tilde{x}}
$$

This term must be positive, otherwise the Nash equilibrium of the quantity game will be unstable. This assumption is common in the literature (Brander \& Spencer 1983). It is known as the Routh-Hurwicz condition.

To interpret the meaning of the denominator, note that

$$
\frac{\partial^{2} \pi}{\partial L^{2}}=R_{1,1} f_{1} f_{1}+R_{1} f_{1,1}
$$

and

$$
\frac{\partial^{2} \pi}{\partial L \partial M}=R_{1,1} f_{1} f_{2}+R_{1} f_{1,2}
$$


As long as the impact of the worker input on the marginal profit of workers exceeds the impact of the managerial input on the marginal profit of workers, the denominator will be positive.

The Routh-Hurwicz condition, together with the assumptions that $R_{1,2}<$ 0 and $\tilde{R}_{1,2}<0$, imply that the sign of $\tilde{L}_{2}^{* *}$ is the same as the sign of $f_{2}\left(R_{1,1} f_{1} f_{1}+R_{1} f_{1,1}\right)-f_{1}\left(R_{1,1} f_{1} f_{2}+R_{1} f_{1,2}\right)$. After simplification, the numerator can be written as $R_{1}\left(f_{1,1} f_{2}-f_{1,2} f_{1}\right)$. Given the assumption that $f_{1,2} \geqslant 0$ and $f_{1,1}<0$, this expression is positive. Therefore, we get $\tilde{L}_{2}^{* *}<0$.

\subsubsection{Over-management and cost minimisation in the se- quential game}

In the static benchmark case, the equilibrium (and also cost minimising) ratio of workers to management was implicitly defined by the condition:

$$
\frac{f_{1}}{f_{2}}=\frac{w}{r}
$$

In the bilateral commitment game, applying the envelope theorem yields:

$$
\frac{R_{1} f_{1}}{R_{1} f_{2}+R_{2} \tilde{f}_{1} \tilde{L}_{2}^{* *}}=\frac{w}{r}
$$

Remember the assumption that $R_{2}<0$. Also, we have established that if $f_{1,2}>0$, then $\tilde{L}_{2}^{* *}<0$. Thus, it follows that $R_{2} \tilde{f}_{1} \tilde{L}_{2}^{* *}>0$. We can now use the same argument as in the unilateral commitment case to assert that, for a given level of output, more management will be used relative to the cost minimising bundle for that level of output.

\subsection{Cobb-Douglas example}

We now assume a specific functional form which satisfies the assumptions discussed earlier. Consider quadratic revenue functions: $R(x, \tilde{x})=$ $(Z-x-\tilde{x}) x$ and $\tilde{R}(\tilde{x}, x)=(Z-x-\tilde{x}) x$. Also suppose that the firms' production functions are Cobb-Douglas: $x=M^{\alpha} L^{1-\alpha}$ and $\tilde{x}=\tilde{M}^{\alpha} \tilde{L}^{1-\alpha}$. 
To simplify computations, we assume that $Z=1$ and $\alpha=\frac{1}{2}$. Therefore, the payoff functions of firms $A$ and $B$ take the form:

$$
\begin{aligned}
\pi & =(1-\sqrt{M} \sqrt{L}-\sqrt{\tilde{M}} \sqrt{\tilde{L}}) \sqrt{M} \sqrt{L}-w L-r M \\
\pi & =(1-\sqrt{M} \sqrt{L}-\sqrt{\tilde{M}} \sqrt{\tilde{L}}) \sqrt{\tilde{M}} \sqrt{\tilde{L}}-w \tilde{L}-r \tilde{M}
\end{aligned}
$$

\subsubsection{Simultaneous-move benchmark}

In the simultaneous-move game, the first-order conditions are:

$$
\begin{aligned}
& \frac{\partial \pi}{\partial L}=\frac{1}{2}(1-2 \sqrt{M} \sqrt{L}-\sqrt{\tilde{M}} \sqrt{\tilde{L}}) \frac{\sqrt{M}}{\sqrt{L}}-w=0 \\
& \frac{\partial \pi}{\partial M}=\frac{1}{2}(1-2 \sqrt{M} \sqrt{L}-\sqrt{\tilde{M}} \sqrt{\tilde{L}}) \frac{\sqrt{L}}{\sqrt{M}}-r=0 \\
& \frac{\partial \tilde{\pi}}{\partial \tilde{L}}=\frac{1}{2}(1-\sqrt{M} \sqrt{L}-2 \sqrt{\tilde{M}} \sqrt{\tilde{L}}) \frac{\sqrt{\tilde{M}}}{\sqrt{\tilde{L}}}-w=0 \\
& \frac{\partial \tilde{\pi}}{\partial \tilde{M}}=\frac{1}{2}(1-\sqrt{M} \sqrt{L}-2 \sqrt{\tilde{M}} \sqrt{\tilde{L}}) \frac{\sqrt{\tilde{L}}}{\sqrt{\tilde{M}}}-r=0
\end{aligned}
$$

To see to whether these equations would yield a maximum or minimum, we need to check the second-order conditions. The second-order derivatives of firm $A$ 's payoff function are:

$$
\begin{gathered}
\frac{\partial^{2} \pi}{\partial L^{2}}=-(1-2 \sqrt{M} \sqrt{L}-\sqrt{\tilde{M}} \sqrt{\tilde{L}}+4 L) \frac{\sqrt{M}}{4 L \sqrt{L}} \\
\frac{\partial^{2} \pi}{\partial M^{2}}=-(1-2 \sqrt{M} \sqrt{L}-\sqrt{\tilde{M}} \sqrt{\tilde{L}}+4 M) \frac{\sqrt{L}}{4 M \sqrt{M}} .
\end{gathered}
$$


Symmetric expressions can be derived for firm $B$. It can be shown that, for sufficiently small values of $M$ and $L$, these derivatives will be negative $e^{10}$. Therefore, the solutions to the first-order conditions will maximise profits.

Furthermore, we assign the following numerical values to factor prices: $w=0.1$ and $r=0.2$. The Nash equilibrium inputs and output levels are

$$
\begin{gathered}
M=\tilde{M}=0.1690355937 \\
L=\tilde{L}=0.3380711875 \\
x=\tilde{x}=0.2390524292
\end{gathered}
$$

\subsubsection{Bilateral commitment game}

Next we analyse the bilateral commitment game with payoff functions as specified by (3.14). We solve this game using backward induction. That is, we first compute the Nash equilibrium of the stage-two game, while taking management levels as given. Differentiating stage-two profits with respect to the worker inputs, we get the first-order conditions:

$$
\begin{aligned}
& \frac{\partial \pi}{\partial L}=\frac{\sqrt{M}}{2 \sqrt{L}}(1-\sqrt{M} \sqrt{L}-\sqrt{\tilde{M}} \sqrt{\tilde{L}})-\frac{M}{2}-w=0 \\
& \frac{\partial \tilde{\pi}}{\partial \tilde{L}}=\frac{\sqrt{\tilde{M}}}{2 \sqrt{\tilde{L}}}(1-\sqrt{\tilde{M}} \sqrt{\tilde{L}}-\sqrt{M} \sqrt{L})-\frac{\tilde{M}}{2}-w=0
\end{aligned}
$$

Solving these first-order conditions simultaneously gives us the equilibrium levels of $L$ and $\tilde{L}$ as functions of $M$ and $\tilde{M}$ :

$$
L^{* *}(M, \tilde{M})=\frac{M(\tilde{M}+2 w)^{2}}{\left(3 M \tilde{M}+4 \tilde{M} w+4 M w+4 w^{2}\right)^{2}}
$$

\footnotetext{
${ }^{10}$ These small values make sense, as the value has to be small in order to have positive profits
} 


$$
\tilde{L}^{* *}(\tilde{M}, M)=\frac{\tilde{M}(M+2 w)^{2}}{\left(3 M \tilde{M}+4 \tilde{M} w+4 M w+4 w^{2}\right)^{2}}
$$

We substitute these functions to obtain stage-one profits. Setting $w=0.1$ and $r=0.2$ gives us:

$$
\begin{aligned}
\pi_{i}= & \left(1-\frac{M_{i}\left(M_{j}+0.2\right)+M_{j}\left(M_{i}+0.2\right)}{3 M_{i} M_{j}+0.4 M_{j}+0.4 M_{i}+0.04}\right) \frac{M_{i}\left(M_{j}+0.2\right)}{\left(3 M_{i} M_{j}+0.4 M_{j}+0.4 M_{i}+0.04\right)} \\
& -0.2 M_{i}-0.1 \frac{M_{i}\left(M_{j}+0.2\right)^{2}}{\left(3 M_{i} M_{j}+0.4 M_{j}+0.4 M_{i}+0.04\right)^{2}}
\end{aligned}
$$

In appendix $\mathrm{A}$, we take the first-order conditions and solve them for $M^{* *}$ and $\tilde{M}^{* *}$ to get

$$
M^{* *}=\tilde{M}^{* *}=0.1965087033 .
$$

Substituting $M^{* *}$ and $\tilde{M}^{* *}$ in the stage-two choices of worker inputs yields

$$
L^{* *}=\tilde{L}^{* *}=0.3152454277 .
$$

These correspond to the following output levels:

$$
x^{* *}=\tilde{x}^{* *}=0.2488944962 .
$$

Comparing the bilateral commitment game to the simultaneous-move benchmark, we can see that commitment leads to an increase in the firms' equilibrium output levels. This result is driven by the strategic substitutability of output levels, which is transferred to input choices. Also, note that equilibrium management levels are higher in the sequential-move game. This makes intuitive sense, as management is being used to commit firms to producing more output. Finally, we see that the worker input is lower. Thus, strategic commitment is partially undone by the substitutability between the labour inputs. 


\section{Over-management}

Now we investigate whether this numerical example exhibits over-management. Earlier we defined over-management as an occurrence where more than the cost-minimising amount of management is used to create the equilibrium output. Now we check whether the choice of inputs is cost minimising for the level of output that the firms produce.

Our sequential-move game yields $x^{* *}=0.2488944962$. Assuming a production function $x^{* *}=\sqrt{M} \sqrt{L}$ and input prices $w=0.1$ and $r=0.2$, this output level can be produced at the least cost when $M_{i} \approx 0.172$. This is lower than the subgame-perfect level of management we obtained in the sequential-move game.

\subsubsection{General Input Prices}

\section{Worker to manager ratio}

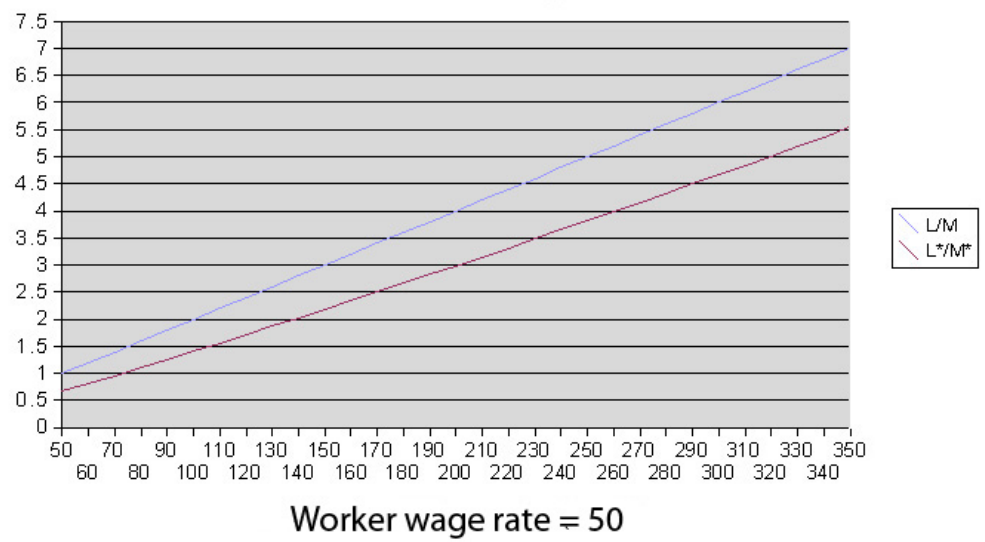

The above graph illustrates the worker management ratio in both the static and sequential move games for a range of managerial wage rates (holding the workers wage rate at $w=50)$. Across the entire range the worker to management ratio is lower in the sequential move game than it is in the static game. This indicates that production is always more management intensive than in the absence of a strategic motive. 


\subsection{Comparison to Literature}

The argument used in this thesis is common in the literature on strategic commitment. A similar model was studied by Brander \& Spencer (1983). In their paper, firms use R\&D as an instrument of strategic commitment. Their model has two important features.

1) Brander \& Spencer (1983) do not assume a production function that includes the strategic variable. They work directly with "inputs". This is justified by the assumption that their input is also an output.

2) In order to have one of their inputs as output, Brander \& Spencer (1983) require that $R \& D$ enters the cost function but not the revenue function. As a result, the only role of investment in $R \& D$ is to reduce costs.

Our setting differs in that firms use two inputs, and thus both inputs enter the revenue function.

\subsection{Conclusion}

The choice of inputs is essential for any firm. Labour is of special interest to us because of its specificities, and the fact that all production processes require the use of labour. The two-stage model analysed above studied important interactions between different labour types within a firm. However, this model is not fully satisfactory, because we had to make strong assumptions about the nature of inputs, the production process and the market. The next chapter discusses these limitations. 


\section{Chapter 4}

\section{Weakening the assumptions of model one}

The two-stage model of chapter 3 illustrated the possibility that management could be used for strategic commitment. However, the result relied on a number of unsatisfactory assumptions, namely:

- the horizon of the game;

- the magnitude of management and worker irreversibility;

- the magnitude of management and worker observability.

\subsection{Extending the horizon of the game}

The two-stage game assumes that firms only compete once. Hypothetically, the results of the two-stage game will hold over any finite horizon as long as the managerial input is fixed. In the original example of department stores, it was stated that the managerial input could be fixed for up to a month, while in the scope of a week the worker input is flexible. Thus, the two-stage game would be an accurate representation of reality only if the firm operates for a month. However, department stores usually operate over a much longer time span, and, more importantly, they aim to operate well into the future. Since their objective is to maximise lifetime 
profit, the horizon of the two-stage model is highly unrealistic. Therefore, we need to investigate whether we can broaden our description of the managerial input and the objective of the firm, while maintaining the result of over-management.

One way to extend our results to a longer horizon is by having the twostage game played repeatedly over time. In this repeated game, the managerial input would be set in a completely flexible fashion at certain discrete points in time. Once it has been determined, it is completely irreversible until the next readjustment. Output is produced and sold at other points in time, after the managerial input is set.

This description of the choice of managerial input is still unrealistic. Management is never either entirely flexible or entirely unadjustable. There are no such discrete periods where it is costless to change the managerial input and other periods where it is impossible to change it. Thus, we would prefer a method that more accurately describes the actual costs associated with adjustment of management.

There is another problem with repeating the two-period game an infinite number of times. In particular, players may use trigger strategies. Such strategies may enable firms to collude, and so our result of overmanagement will unravel. Moreover, trigger strategies give rise to many other subgame-perfect equilibria. A favourable solution to our descriptive problem will be one that offers a reasonable way of side-stepping the multiplicity of equilibria arising from the use of trigger strategies.

\subsubsection{Interpretation of the infinite horizon game}

Previously we argued that a two-stage game would provide a good starting point for illustrating over-management. Now that the phenomenon has been analysed in a two-stage framework, it is important to see if the results can be extended to a more realistic time horizon. We could use two modeling approaches, a finite horizon and infinite horizon.

A finite horizon game has a pre-determined endpoint. By stating that the game has a finite horizon, we assume that players know both that the game will finish, and when the game will finish.

An infinite horizon game does not have a defined endpoint. There are two 
ways to view what this implies about the game: the firms may believe the game will go on forever or the firms may not know when the game will end.

Assuming that the owners of a firm believe the game would last forever is unrealistic. All interactions have an endpoint, and agents likely realise that the game will eventually come to an end. The second way of interpreting an infinite horizon makes more intuitive sense. If the firm believes that competition will end at some point, but does not know the exact time of this event, they will assign a positive probability to the firm operating at any point in the future.

This view of the finite horizon game may not suit the decisions of a small owner-operated firm, where the owner aims to retire in a certain year and remove himself from his business. 1 . However, in the case of a large department store, the owners are in fact a group of shareholders. These shareholders delegate authority to a board of directors, who in turn are interested in profit maximisation. ${ }^{2}$ In this case, there is no reason to expect that the board of directors or shareholders will wind down operations at a set point in time.

The idea that a firm competing in a finite but uncertain number of periods maximises an objective function equivalent to that of an infinitely-lived firm is supported by the methodological discussion of (Rubinstein 1991). Rubinstein claims that infinite horizon games are a good predictor of players' behaviour when the end point of a game is unknown.

Why are an infinite horizon game and a finite horizon game with an unknown endpoint conceptually equivalent? First, consider the infinite horizon game. In that setting, the firm wishes to maximises their lifetime profit, which is the sum of the discounted profits realised throughout time. Since there is an infinite number of periods, lifetime profit is given by an infinite sum. Let $\pi_{t}$ denote the instantaneous profit realised at time $t$. From the viewpoint of period 0 , their lifetime profit is:

$$
\Pi=\sum_{t=0}^{\infty} \delta^{t} \pi_{t}
$$

\footnotetext{
${ }^{1}$ Such a firm is more likely to be part of a monopolistically competitive retail industry

${ }^{2}$ The true incentives of a board of directors is not the subject of this thesis
} 
Here $\delta$ is the firm's discount factor. It reflects the fact that firms do not value a dollars profit tomorrow as much as they do a dollars profit today ${ }^{3}$

When a firm knows they play a finite horizon game, the sum will be over a finite number of instantaneous profits. If the final period is unknown, players cannot act in a way that is consistent with a regular finite horizon game. Suppose that there is a constant probability $p$ that the game will end in the next round, and thereafter firms will stop receiving profits. If the game carries on to period $t+1$, they anticipate a profit of $\pi_{t+1}$ (Fischer 1989). Assuming a common discount factor $\delta$, the expected lifetime profit of a firm is given by:

$$
\Pi^{*}=\sum_{t=0}^{\infty}(\delta p)^{t} \pi_{t}
$$

Here the probability of the firm shutting down scales down the same infinite sum that the firm would have received if it was playing an infinite horizon game. The effective discount factor is now $\delta p$.

Therefore, a finite horizon game with an unknown end point can be modeled as an infinite horizon game, where the discount factor incorporates the probability that the game will end in the subsequent period. So the choice between finite horizon and infinite horizon models will depend on whether we believe that competition has a well-defined, known endpoint.

Returning to the example of department stores, it seems reasonable to assume that competition occurs without knowledge of a fixed end date. Consequently, using an infinite horizon model seems appropriate for our purpose.

\subsubsection{Infinite horizon model}

Next we specify the elements of the infinite horizon model, including information, payoffs and strategies. The aim is to generalise the two-stage setting, while preserving the results from the previous chapter. The twostage model captured the intuition of over-management. However, to

\footnotetext{
${ }^{3}$ This can be justified in a number of ways, firstly the missed interest earnings on the dollar, secondly, the lost buying power from inflation and thirdly, a bias for present consumption
} 
broaden the applicability of our results, it is important to extend the domain of models that support these results.

The first step in extending the two-stage model is to investigate whether it fits in an infinite horizon framework. This will facilitate the generalisation of our results.

Potentially we could have an infinite horizon model in which firms repeatedly play the two-stage game from the previous chapter. This has the advantage of including the two-stage result as a special case when the discount factor is equal to zero. However, this approach was already dismissed as descriptively unrealistic, since management is usually not adjustable costlessly in pre-determined periods.

A more plausible way of extending our model to an infinite horizon would require taking a step backward and looking at the set of the underlying main assumptions. These assumptions were:

- irreversibility;

- observability by other firms; and

- ability to shift the output reaction function with the irreversible/observable choice variable.

Beyond standard economic assumptions, these were the conditions that we imposed in the previous chapter. To set up the two-stage model, we assumed specific definitions of irreversibility, observability and output commitment. Applying them to the managerial input gave us the result of over-management. These conditions are stronger than what is required for over-management to occur. They could be weakened without destroying our fundamental result of over-management.

\section{On irreversibility}

Previously the managerial input was deemed to be irreversible because the firm could not change it within the given time frame. This irreversibility implied that management was also observable, and it had commitment value as long as it generated higher equilibrium output and reduced the 
equilibrium output of other firms. We need to modify these ideas in the context of an infinite horizon setting.

An input is never fully irreversible. In the case of the managerial input, it is always possible to decrease it by paying a large enough (but finite) sum of money to remove a manager. It is also possible to increase this input by paying a large sum of money to attract a talented new manager. Therefore, the managerial input can be changed, but it may be costly to do so.

In the previous model, it was impossible to adjust the managerial input. This is equivalent to assuming that the cost of changing the level of management was infinite. With infinite costs, it would never be optimal to change the level of management as the benefit of doing so is finite. As a result, the managerial input can be treated as fixed.

In chapter 2 , the cost of changing an input over time was termed "adjustment cost". We claimed that the managerial input has a relatively high adjustment cost. This was justified by the difficulty of changing the managerial input at both the extensive and intensive margins. In the two-stage model, the extreme assumption of infinite adjustment cost (irreversible management) was made to simplify the analysis. In an infinite-horizon setting, this assumption is descriptively unrealistic, and so the idea of a finite adjustment cost will now be used.

Perfect irreversibility is equivalent to having an infinite adjustment cost, and a perfectly reversible input has an adjustment cost of zero. When the managerial input has a positive but finite adjustment cost, it is partially irreversible. The higher the adjustment cost, the less reversible the input becomes.

The idea of an adjustment cost instead of complete irreversibility has been used previously in the strategic investment literature. For commitment using capacity stocks see (Reynolds 1987).

\section{On observability}

Observability refers to the information available to the firms at the time they make their input/output decisions.

In the previous model, the fixed nature of the managerial input was enough to ensure its observability. An infinite horizon model gives us the oppor- 
tunity to modify and generalise this idea. When the firm makes their choice of managerial and worker inputs, it is unlikely that its opponents would be able to observe the current choice of worker and/or managerial input. However, firms may be able to observe lagged values of their opponents' inputs. The observability of lagged input choices may come from industrial spying, or publicly released information.

Thus, in the next chapter observability will refer to the knowledge of the lagged values of the managerial and worker inputs. These lagged values will be payoff relevant only when inputs are costly to adjust. This implies that (partial) irreversibility and observability are closely interrelated.

On the relationship between management, workers, and output.

Given our new notions of irreversibility and observability, the final necessary ingredient is that management shifts the output reaction function. In the previous model, we required that the firm's managerial input and the opponent's worker inputs are strategic substitutes. Then a firm can increase its profit by committing to a higher level of output. This condition is still essential. If the managerial input cannot lead to a higher level of output, then it is not going to be used as a strategic resource. 


\section{Chapter 5}

\section{Model Two}

The two-stage game analysed in the previous chapter involved three strong assumptions:

1. The managerial input is infinitely costly to adjust.

2. The worker input is costless to adjust.

3. The game ends after the second period.

The aim of this chapter is to show that the result of over-management continues to hold when these assumptions are relaxed. We will investigate the role of the adjustment cost and timing of management for inducing over-management. We illustrate that, in a two stage model, a finite cost of adjusting the managerial input is sufficient to deliver over-management.

\subsection{Finite adjustment costs of management}

\subsubsection{Discussion}

In real life, adjusting management is not costless. However, such adjustments are not infinitely costly as assumed in the previous model. Firms' management levels do change over time. In large companies, managers 
can be moved between firm divisions, or even promoted to a different role. Sometimes they can even be removed. This suggests that the cost of changing the managerial input is finite.

Nevertheless, this cost is non-negligible. The process of adjusting management is slow: adding managers involves long hiring procedures and training. Often firms reduce their managerial input by waiting for managers to leave and then not replacing them, rather than by directly removing managers from their positions. This adjustment is usually slower than the underlying changes in the marketplace. Consumer demand is fickle: it is heavily influenced by consumer expectations and the general state of the economy. A sudden fall in consumer confidence can lead to a big change in sales, but firms rarely respond with a matching adjustment of management.

Finite but non-negligible adjustment costs of the managerial input have important implications for the firm's choice of management. If management levels can be changed while the firm is choosing its output, then they cannot deliver full commitment. Nevertheless, sufficiently high adjustment costs ensure partial irreversibility. The cost to changing management will be weighed against the subsequent strategic benefits arising from this change. If a player chooses a higher level of management today, he will have a disincentive to reduce his management in the future. In this way, firms can partially commit to higher output.

The plausibility of the modeling approach adopted in this chapter makes it more appealing than the previous notion of irreversibility. We will demonstrate that this weaker notion still allows us to explain the existence of over-management.

In this example we will keep any adjustment cost of the worker input implicitly equal to zero. In appendix $\mathrm{E}$ we also derive the Euler equations for a four state model in which the worker input does have a positive adjustment cost. However, we believe that this adjustment cost is not very high, and therefore the worker input is not observable or particularly irreversible.

\subsubsection{Summary argument}

The argument is as follows: 
1. the management input influences the marginal productivity of other inputs;

2. management is costly to change over time;

3. previous management levels are observable. Therefore,

4. management has commitment value.

The purpose of our model is to illustrate the logical link between premises $1,2 \& 3$ and our conclusion 4 .

\subsection{Notation}

Our notation is similar to Coury \& Petkov (2007). Consider a function $f$ that has $n$ arguments. A subscript $i$ denotes the partial derivative of that function with respect to the $i$-th argument. For example, $f_{2}(a, b)$ is used to denote the partial derivative $\partial f(a, b) / \partial b$. Superscripts are reserved for time.

\subsubsection{Choice variables}

Suppose that two players, firms $A$ and $B$, compete in an infinite-horizon quantity game. At time $t$ each firm produces its output from two labour inputs, workers and managers. The period- $t$ worker inputs of $A$ and $B$ are denoted by $L^{t}$ and $\tilde{L}^{t}$, respectively. The period-t managerial inputs of $A$ and $B$ are denoted by $M^{t}$ and $\tilde{M}^{t}$, respectively.

\subsection{Infinite horizon model}

\subsubsection{Setup}

We assume that any change in management between successive periods gives rise to an adjustment cost. These costs link the firms' profits at time 
$t$ to the management levels at time $t-1$. Because of this link the past history of this dynamical system can be summarised by the previous levels of management. In other words, $M^{t-1}$ and $\tilde{M}^{t-1}$ constitute period- $t$ state variables. Importantly, these variables are payoff-relevant, as in the minimum state variable literature of McCallum (1999)).

In contrast, adjusting the worker input over time does not incur any costs. This implies that lagged worker input is not payoff relevant and therefore not a state variable. $L^{t-1}$ and $\tilde{L}^{t-1}$ may give the firm some information about the rationality of its opponent. Our underlying assumption is that all agents are rational. Given that rationality is common knowledge, the value of the worker input in period $t-1$ does not provide any information about the value of inputs in period $t$.

\section{Payoffs}

The instantaneous payoff function describes a firm's profit at time $t$ as a function of their choice of inputs, the competitor's choice of inputs and the state variables. In our model, the instantaneous payoff functions of a firms $A$ and $B$ are defined as $\pi\left(L^{t}, M^{t}, \tilde{L}^{t}, \tilde{M}^{t}, M^{t-1}, \tilde{M}^{t-1}\right)$ and $\tilde{\pi}\left(\tilde{L}^{t}, \tilde{M}^{t}, L^{t}, M^{t}, \tilde{M}^{t-1}, M^{t-1}\right)$, respectively.

As the firms are competing over an infinite horizon, at a given point in time they wish to maximise the infinite sum of discounted future profits:

$\Pi=\sum_{t=0}^{\infty} \delta^{t} \pi\left(L^{t}, M^{t}, \tilde{L}^{t}, \tilde{M}^{t}, M^{t-1}, \tilde{M}^{t-1}\right), \quad \tilde{\Pi}=\sum_{t=0}^{\infty} \delta^{t} \tilde{\pi}\left(\tilde{L}^{t}, \tilde{M}^{t}, L^{t}, M^{t}, \tilde{M}^{t-1}, M^{t-1}\right)$.

Here $\delta \in(0,1)$ is a common discount factor. We will refer to $\Pi$ and $\tilde{\Pi}$ lifetime profits.

\section{Solution concept}

When modeling over-management, the appropriate solution concept is that of a Markov Perfect Equilibrium (MPE). It accounts for the use of management as an instrument of strategic commitment. Moreover, it helps us 
avoid the multiplicity of equilibria associated with trigger strategies. This solution concept assumes that the players' strategies are time-invariant functions of the payoff relevant states:

$$
\begin{aligned}
M^{t}=f\left(M^{t-1}, \tilde{M}^{t-1}\right), & \tilde{M}^{t}=\tilde{f}\left(\tilde{M^{t-1}}, M^{t-1}\right) \\
L^{t}=g\left(M^{t-1}, \tilde{M}^{t-1}\right), & \tilde{L}^{t}=\tilde{g}\left(\tilde{M}^{t-1}, M^{t-1}\right) .
\end{aligned}
$$

Note that any MPE is also subgame perfect: the strategies will be optimal regardless of past history.

\subsubsection{Analysis}

\section{Recursive formulation}

To characterise the MPE of this game, we first need to formulate the problem recursively. Recursive formulation is attained with the help of Bellman equations, which define a relationship between the value of the game in two successive periods. Let $V$ and $\tilde{V}$ be the players' value functions: they define the equilibrium lifetime payoff of the firms as functions of the current state variables. As already discussed, the state variables of this model are the previous period's management levels.

The agents are assumed to have rational expectations: they correctly anticipate the behaviour of their opponent. Given our conjectures about the equilibrium strategies, the Bellman equations of firms $A$ and $B$ take the form:

$$
\begin{aligned}
V\left(M^{t-1}, \tilde{M}^{t-1}\right)= & \max _{L^{t}, M^{t}}\left\{\pi\left(L^{t}, M^{t}, \tilde{g}\left(\tilde{M}^{t-1}, M^{t-1}\right), \tilde{f}\left(\tilde{M}^{t-1}, M^{t-1}\right), M^{t-1}, \tilde{M}^{t-1}\right)\right. \\
& \left.+\delta V\left(M^{t}, \tilde{f}\left(\tilde{M}^{t-1}, M^{t-1}\right)\right)\right\}
\end{aligned}
$$

and 


$$
\begin{aligned}
\tilde{V}\left(\tilde{M}^{t-1}, M^{t-1}\right)= & \max _{\tilde{L}^{t}, \tilde{M}^{t}}\left\{\tilde{\pi}\left(\tilde{L}^{t}, \tilde{M}^{t}, g\left(M^{t-1}, \tilde{M}^{t-1}\right), f\left(M^{t-1}, \tilde{M}^{t-1}\right), \tilde{M}^{t-1}, M^{t-1}\right)\right. \\
& \left.+\delta \tilde{V}\left(\tilde{M}^{t}, f\left(M^{t-1}, \tilde{M}^{t-1}\right)\right)\right\}
\end{aligned}
$$

Moreover, our conjectures must be consistent with profit maximisation and rational expectations. Therefore, firm $A^{\prime}$ 's strategies must satisfy:

$$
\begin{aligned}
& g\left(M^{t-1}, \tilde{M}^{t-1}\right)=\arg \max _{L^{t}}\left\{\pi\left(L^{t}, f\left(M^{t-1}, \tilde{M}^{t-1}\right), \tilde{g}\left(\tilde{M}^{t-1}, M^{t-1}\right), \tilde{f}\left(\tilde{M}^{t-1}, M^{t-1}\right), M^{t-1}, \tilde{M}^{t-1}\right)\right. \\
& \left.\quad+\delta V\left(f\left(M^{t-1}, \tilde{M}^{t-1}\right), \tilde{f}\left(M^{t-1}, M^{t-1}\right)\right)\right\}
\end{aligned}
$$

and

$$
\begin{aligned}
& f\left(M^{t-1}, \tilde{M}^{t-1}\right)=\arg \max _{M^{t}}\left\{\pi\left(g\left(M^{t-1}, \tilde{M}^{t-1}\right), M^{t}, \tilde{g}\left(\tilde{M}^{t-1}, M^{t-1}\right), \tilde{f}\left(\tilde{M}^{t-1}, M^{t-1}\right), M^{t-1}, \tilde{M}^{t-1}\right)\right. \\
& \left.\quad+\delta V\left(M^{t}, \tilde{f}\left(M^{t-1}, M^{t-1}\right)\right)\right\} .
\end{aligned}
$$

Firm $B^{\prime}$ s strategies must satisfy analogous conditions.

The recursive relationship defined by the Bellman equations can be used to study the problem of choosing inputs. An increase in management $M^{t}$ will have several effects on the lifetime profit of firm $A$. The first effect would be a change in its period $t$ instantaneous profit $\pi\left(L^{t}, M^{t}, \tilde{L}^{t}, \tilde{M}^{t}, M^{t-1}, \tilde{M}^{t-1}\right)$. In the subsequent period, there will be an effect on firm $A^{\prime}$ 's adjustment costs, as well as a strategic effect, as firm $B$ will change its behaviour as a result of $A^{\prime}$ s deviation. These future effects are captured through $A^{\prime}$ s continuation value function $V\left(M^{t}, \tilde{f}^{t}\left(\tilde{M^{t}-1}, M^{t-1}\right)\right)$.

If the payoff consequences of this action go in different directions in period $t$ and $t+1$, firm $A$ will face an intertemporal trade-off. We will show that this trade-off parallels the trade-off arising in the two-stage game. The previous chapter demonstrated that firms competing in strategic substitutes can use management as an instrument of strategic commitment to gain a 
first-mover advantage. In the infinite horizon setting, players have similar incentives. As long as a higher level of management can commit the firms to higher output, then equilibrium management will be set at higher levels than in the static game.

\section{Deriving the equilibrium conditions}

Firm $A$ 's choices must satisfy two first order conditions: one that defines optimal worker input at time $t$, and one that defines optimal managerial input at time $t$. These are both obtained by differentiating the right-hand side of firm $A$ 's Bellman equation with respect to the relevant choice variables.

The first order condition for workers is $\pi_{1}^{t}=0$. It states that the worker input is chosen so that its current marginal revenue product is equal to the current marginal cost of this input. This condition is identical to the one derived in the standard static game.

The first order condition for management is more interesting. It takes the form:

$$
\pi_{2}^{t}+\delta V_{1}^{t+1}=0 .
$$

It states that the optimal choice of management at time $t$ depends on how it influences $A^{\prime}$ 's current profit, and how it affects $A^{\prime}$ 's continuation payoff as a state variable. If the value function is increasing in the firm's lagged management, then the firm has an incentive to hire more managers than in the static game (for a given level of output). Thus, as long as $V_{1}^{t+1}>0$ our result of over-management will hold $\left.\right|^{1}$

Next we consider a marginal change in the state variables. ${ }^{2}$ Lagged management levels $M^{t-1}, M^{t-1}$ have a direct effect on the players' payoffs, and also an indirect effect through the their choice variables. However, profit maximisation allows us to appeal to the envelope theorem. Thus, we can focus only on the direct effect of the state on the payoffs. Differentiating

\footnotetext{
${ }^{1}$ By the mean-value theorem (Brander \& Spencer 1983)

${ }^{2}$ Note this is equivalent to looking at how the previous levels of management influence the firms current choice of inputs
} 
the Bellman equations with respect to the state variables on the optimal path gives us the players' envelope conditions

$$
\begin{aligned}
& V_{1}^{t}=\pi_{3}^{t} \tilde{g}_{2}^{t}+\pi_{4}^{t} \tilde{f}_{2}^{t}+\pi_{5}^{t}+\delta V_{2}^{t+1} \tilde{f}_{2}^{t} \\
& V_{2}^{t}=\pi_{3}^{t} \tilde{g}_{1}^{t}+\pi_{4}^{t} \tilde{f}_{1}^{t}+\pi_{6}^{t}+\delta V_{2}^{t+1} \tilde{f}_{1}^{t}
\end{aligned}
$$

Since the value functions are time invariant, we can combine the two first order conditions and the two envelope conditions to derive the Euler equation for firm $A$ 's problem. Substituting out the derivatives of $V$ and moving forward by 2 periods gives us:

$$
\begin{aligned}
0=\pi_{2}^{t} & +\delta\left(\pi_{3}^{t+1} \tilde{g}_{2}^{t+1}+\pi_{5}^{t+1}\right)+\delta \tilde{f}_{2}^{t+1}\left\{\pi_{4}^{t+1}+\delta\left(\pi_{3}^{t+2} \tilde{g}_{1}^{t+2}+\pi_{6}^{t+2}\right)\right\} \\
& -\frac{\delta \tilde{f}_{2}^{t+1} \tilde{f}_{1}^{t+2}}{\tilde{f}_{2}^{t+2}}\left(\pi_{2}^{t+1}+\delta\left(\pi_{3}^{t+2} \tilde{g}_{2}^{t+2}+\pi_{5}^{t+2}\right)\right) .
\end{aligned}
$$

The Euler equation can be decomposed into the following elements.

- The term $\left[\pi_{2}^{t}+\delta\left(\pi_{3}^{t+1} \tilde{g}_{2}^{t+1}+\pi_{5}^{t+1}\right)\right]$ captures the direct payoff effect and the effect through worker adjustment of a marginal deviation from the equilibrium management level.

- The term $\left[\delta^{2} \tilde{f}_{2}^{t+1}\left(\pi_{3}^{t+2} \tilde{g}_{1}^{t+2}+\pi_{4}^{t+2} \tilde{f}_{1}^{t+2}+\pi_{6}^{t+2}\right)\right]$ captures payoff effect as a result of $B^{\prime}$ s subsequent adjustment of management.

- The term $\left[-\frac{\delta \tilde{f}_{2}^{t+1} \tilde{f}_{1}^{t+2}}{\tilde{f}_{2}^{t+2}}\left(\pi_{2}^{t+1}+\delta\left(\pi_{3}^{t+2} \tilde{g}_{2}^{t+2}+\pi_{4}^{t+2} \tilde{f}_{2}^{t+2}+\pi_{5}^{t+2}\right)\right)\right]$ captures the payoff effect that occurs as $A$ readjust its management in expectation of $B^{\prime}$ s reaction.

Managerial input is optimally chosen optimally when these three marginal payoff effects sum up to zero. This implies that a rational player has no incentive to deviate from its strategy.

Fundamentally, the Euler equation suggests that the required assumption for over-management is that managers is strategic substitutability. This is 
the same result Jun \& Vives (2004) found for capital, and it can be generalised for any game with some type of Stakelberg leadership potential (Jun \& Vives 2001).

\subsection{Motivation for the numerical example}

When solving infinite horizon games it is common to adopt production functions, inverse demand functions and costs that yield linear-quadratic instantaneous payoffs. The reason is that in linear-quadratic problems we know that there will be an equilibrium involving strategies that are linear in the state variables. This simplifies numerical computations.

One way to set up our problem as linear quadratic is to assume a linear inverse demand function, a linear production function, and linear input costs. This implies that the firm's revenue function is quadratic, and thus profits will be quadratic in inputs. However, this formulation does not yield over-management.

Generally, in the two-stage model we could sign $\tilde{L}_{2}$ given the sign of $R_{1}\left(f_{1,1} f_{2}-f_{1,2} f_{1}\right)$. When our production function is linear, both $f_{1,1}$ and $f_{1,2}$ are equal to zero. As a result, $\tilde{L}_{2}=0$ and the firm does not deviate from the cost minimising bundle.

We can also illustrate this through the following two-stage example.

\subsubsection{Two-period example with perfect substitutability}

Suppose that we have a production function which is linear in the two labour inputs, workers $(L)$ and managers $(M)$. Thus, it takes the form $x=\mu L+\eta M$, where $\mu$ is the marginal product of workers and $\eta$ is the marginal product of management. For simplicity we will set $\eta=\mu=1$. However, input prices are asymmetric. In this example, the marginal cost of a worker is $w=1$ while the marginal cost of a manager is $r=2$.

The revenue function of firm $A$ is quadratic and takes the form $R=(Z-$ $(L+M)-(\tilde{L}+\tilde{M}))(L+M)$. We will set $Z=101$. Given our cost specification, the firm's profit function will be linear-quadratic: 


$$
\pi=(101-(L+M)-(\tilde{L}+\tilde{M}))(L+M)-L-2 M
$$

Firm $B$ 's profit function is symmetric:

$$
\tilde{\pi}=((101-(\tilde{L}+\tilde{M})-(L+M))(\tilde{L}+\tilde{M})-\tilde{L}-2 \tilde{M}
$$

\section{Simultaneous-move benchmark}

In the simultaneous-move game, the first order conditions are:

$$
\begin{gathered}
\frac{d \pi}{d L}=100-(2 L+2 M)-(\tilde{L}+\tilde{M})=0 \\
\frac{d \pi}{d M}=99-(2 L+2 M)-(\tilde{L}+\tilde{M})=0 \\
\frac{d \tilde{\pi}}{d \tilde{L}}=100-(2 \tilde{L}+2 \tilde{M})-(L+M)-=0 \\
\frac{d \tilde{\pi}}{d \tilde{M}}=99-(2 \tilde{L}+2 \tilde{M})-(L+M)=0
\end{gathered}
$$

In this static game, we have a corner solution: in equilibrium $M$ and $\tilde{M}$ will be set equal to zero. This is driven by the fact that both inputs have identical marginal products, but the marginal cost of the managerial input is higher than that of the worker input. Therefore, we can set the managerial inputs equal to zero and solve for the two firms' equilibrium worker inputs. This gives us

$$
L=\frac{100}{3}, \tilde{L}=\frac{100}{3} .
$$

The equilibrium profit of each firm is 1111.11. 


\section{When one firm commits}

Next we consider the case when firm $A$ commits by choosing a positive level of management $M>0$, while firm $B$ still sets $\tilde{M}=0$. Solving for $L$ and $\tilde{L}$, we obtain worker levels as functions of $M$ :

$$
L=\frac{100}{3}-M, \tilde{L}=\frac{100}{3}
$$

In this case, the commitment power of management stems from the requirement that $L$ must be greater than or equal to zero. Treating $M$ as a parameter, we can see that as long as $M<100 / 3$ the choice of $L$ will be positive and the choice of $\tilde{L}$ will remain at $\frac{100}{3}$. However, if $M>\frac{100}{3}$ the equilibrium outcome will violate the above first order conditions. Therefore, $\tilde{L}=\frac{100}{3}$ will not be a best response as $L$ cannot be negative. Effectively, the non-negativity constraint on $L$ makes the output associated with management irreversible when $M>100 / 3$.

To show the commitment power of $M$ in this game, we set $L=0$ as well as $\tilde{M}=0$ and then study the choice of $M$. If the equilibrium value of $M$ exceeds $\frac{100}{3}$ then we need to compare two corner solutions: one where $M=0$ and one where $L=0$. This will allow us to determine the choice of firm $A$ in the first stage of the game.

We apply backward induction while conjecturing that $L=0$ and $\tilde{M}=0$. Firm $B^{\prime}$ s profit function takes the form:

$$
\tilde{\pi}=(101-\tilde{L}-M) \tilde{L}-\tilde{L} .
$$

The corresponding first-order condition is:

$$
\frac{d \tilde{\pi}}{d \tilde{L}}=100-2 \tilde{L}-M=0 .
$$

Firm $B^{\prime}$ s best response function takes the form:

$$
\tilde{L}=\frac{100-M}{2}
$$

Firm $A$ realizes that their choice of managerial input will affect Firm $B^{\prime}$ s worker input, and thereby output. In particular, for every unit of manage- 
rial input $M$ used, Firm $B$ will reduce their worker input by $1 / 2$. Firm $A$ will takes this into account. Its stage- 1 profit function will have the following form:

$$
\pi=\left(101-M-\frac{100-M}{2}\right) M-2 M
$$

Its first-order condition is given by:

$$
\frac{d \pi}{d M}=49-M=0
$$

Therefore, the profit maximising level of $A^{\prime}$ s management would be $M=$ 49.

To figure out whether firm $A$ will choose to commit by setting $M=49$, we need to compare its profit to the case when $M=0$. Earlier we found that when its managerial input is $0, A^{\prime}$ s equilibrium profit is $\pi=1111.11$. If, however, firm $A$ chooses $M=49$, its equilibrium payoff is $\pi=1200.5$. Thus, the equilibrium of the unilateral commitment game will involve over-management. The corresponding equilibrium profit of firm $B$ is $\tilde{\pi}=$ 599.25 .

\section{When both firms commit}

Now suppose that both firms can choose their management levels upfront. Again, for the managerial input to play a commitment role, firms have to choose management levels above $100 / 3$.

When analyzing this game, we start by looking at the case where the worker non-negativity constraint is binding: $L=\tilde{L}=0$. Thus, the profit function of firm A will be given by:

$$
\pi=(101-M-\tilde{M}) M-2 M
$$

It implies the following first-order condition:

$$
\frac{d \pi}{d M}=99-2 M-\tilde{M}=0
$$


Given symmetry, in equilibrium we obtain $M=33, \tilde{M}=33$.

However, when $M=33, \tilde{M}=33$, setting $L=0$ is not a best response. Therefore, this equilibrium is not subgame perfect. When both firms are choosing management up-front, the game becomes equivalent to the static benchmark: in the subgame perfect equilibrium, both firms set $M=\tilde{M}=$ 0 and $L=\tilde{L}=100 / 3$, thus producing $100 / 3$ units of output.

\subsubsection{Two-period example with quadratic costs}

\section{Justification for quadratic costs}

In microeconomics we typically assume that the cost of labour inputs is linear. Generally, staff is paid per hour or day, rather than as some nonlinear function of work time. However, maintaining this assumptions would create technical difficulties in an infinite horizon framework. The reason is that the linear production functions imply perfect substitutability of inputs. Thus, linear input costs would necessarily lead to corner solutions as demonstrated in the previous example.

To resolve this issue, we will assume quadratic input costs. This assumption can be justified in two ways: introduce imperfect competition in the input markets, or argue that this is a "transformed" problem based on underlying non-linear production functions..

The first approach is tempting, given that it involves the plausible assumption that firms have market power in the labour market. However, overmanagement stemming from monopsony power does not appear to be directly comparable to our two-stage model in chapter three, as it assumes assumed perfect competition in the factor markets. Therefore, we will take the second approach.

Assume that firm $A^{\prime}$ s production function at time $t$ takes the form $x^{t}=$ $\left(l^{t}\right)^{\frac{1}{2}}+\left(m^{t}\right)^{\frac{1}{2}}$. Suppose that production costs are linear in the factor inputs: $C\left(x^{t}\right)=w l^{t}+r m^{t}$. Furthermore, assume that there is a cost of adjusting the managerial input over time, which is now given by $\frac{\psi}{2}\left(\left(m^{t}\right)^{\frac{1}{2}}-\left(m^{t-1}\right)^{\frac{1}{2}}\right)^{2}$. Using a tilde to denote firm $B^{\prime}$ s variables, firm $A^{\prime}$ s instantaneous payoff at time $t$ is: 


$$
\begin{aligned}
\pi^{t} & =\left(Z-\left(\left(l^{t}\right)^{\frac{1}{2}}+\left(m^{t}\right)^{\frac{1}{2}}\right)-\left(\left(\tilde{l}^{t}\right)^{\frac{1}{2}}+\left(\tilde{m}^{t}\right)^{\frac{1}{2}}\right)\right)\left(\left(l^{t}\right)^{\frac{1}{2}}+\left(m^{t}\right)^{\frac{1}{2}}\right) \\
& -w l^{t}-r m^{t}-\frac{\psi}{2}\left(\left(m^{t}\right)^{\frac{1}{2}}-\left(m^{t-1}\right)^{\frac{1}{2}}\right)^{2}
\end{aligned}
$$

This game does not fit within a linear-quadratic framework. But if we use transformed variables $L^{t}=\left(l^{t}\right)^{2}$ and $M^{t}=\left(m^{t}\right)^{2}$ the profit function takes a familiar form:

$$
\begin{aligned}
\pi^{t} & =\left(Z-\left(L^{t}+M^{t}\right)-\left(\tilde{L}^{t}+\tilde{M}^{t}\right)\left(L^{t}+M^{t}\right)\right. \\
& -w\left(L^{t}\right)^{2}-r\left(M^{t}\right)^{2}-\frac{\psi}{2}\left(M^{t}-M^{t-1}\right)^{2}
\end{aligned}
$$

\section{Two-period setup}

Suppose that firm $A$ and firm $B$ produce in two periods. The demand function of both firms is linear. It generates revenue functions $R^{t}=(Z-$ $\left.x^{t}-\tilde{x}^{t}\right) x^{t}$ and $\tilde{R}^{t}=\left(Z-x^{t}-\tilde{x}^{t}\right) \tilde{x}^{t}$, respectively. The production functions are linear in managerial and worker inputs: $x^{t}=\mu L^{t}+\eta M^{t}$ and $\tilde{x}^{t}=\mu \tilde{L}^{t}+\eta \tilde{M}^{t}$. Furthermore, we assume that, in period 2, players also incur adjustment costs $\frac{\psi}{2}\left(M^{2}-M^{1}\right)^{2}$ and $\frac{\psi}{2}\left(\tilde{M}^{2}-\tilde{M}^{1}\right)^{2}$. The presence of adjustment costs implies that the choice of period-1 managerial input will affect profits in both periods. In order to ensure that we have an interior solution, the input cost of firm $A$ will be quadratic as discussed above: $C\left(x\left(L^{t}, M^{t}\right)\right)=w\left(L^{t}\right)^{2}+r\left(M^{t}\right)^{2}$

As a result Firm A's profit function at time $t \in\{1,2\}$ takes the form:

$$
\begin{aligned}
& \pi^{t}\left(L^{t}, M^{t}, \tilde{L}^{t}, \tilde{M}^{t}, M^{t-1}\right)=\left(Z-\left(\mu L^{t}+\eta M^{t}\right)-\left(\mu \tilde{L}^{t}+\eta \tilde{M}^{t}\right)\right)\left(\mu L^{t}+\eta M^{t}\right) \\
& -w\left(L^{t}\right)^{2}-r\left(M^{t}\right)^{2}-\frac{\psi^{t}}{2}\left(M^{t}-M^{t-1}\right)^{2}
\end{aligned}
$$

where $\psi^{1}=0, \psi^{2}=\psi$. The profit function of firm $B$ is symmetric. In period 1 , the two firms choose their inputs to maximise their lifetime profits, $\pi^{1}+\delta \pi^{2}$ and $\tilde{\pi}^{1}+\delta \tilde{\pi}^{2}$, respectively, where $\delta$ is a common discount factor. 
In period 2, the firms' objective is to maximise the stage-2 profits $\pi^{2}$ and $\tilde{\pi}^{2}$.

\section{Characterising the subgame-perfect Nash equilibrium}

We solve this game by backward induction. In the second stage, the firms will choose $L^{2}, M^{2}, \tilde{L}^{2}, \tilde{M}^{2}$ in order to maximise their period-2 profits. The stage-two payoff function of firm $A$ is given by:

$$
\begin{aligned}
& \pi^{2}\left(L^{2}, M 2, \tilde{L}^{2}, \tilde{M}^{2}, M^{1}\right)=\left(Z-\left(\mu L^{2}+\eta M^{2}\right)-\left(\mu \tilde{L}^{2}+\eta \tilde{M}^{2}\right)\right)\left(\mu L^{2}+\eta M^{2}\right) \\
& \quad-w\left(L^{2}\right)^{2}-r\left(M^{2}\right)^{2}-\frac{\psi}{2}\left(M^{2}-M^{1}\right)^{2}
\end{aligned}
$$

The payoff function of firm $B$ is given by a symmetric expression.

The optimal choice of each player is characterised by the following first order conditions:

$$
\begin{gathered}
\pi_{1}^{2}=Z-2\left(L^{2}+M^{2}\right)-\left(\tilde{L}^{2}+\tilde{M}^{2}\right)-2 w L^{2}=0 \\
\pi_{2}^{2}=Z-2\left(L^{2}+M^{2}\right)-\left(\tilde{L}^{2}+\tilde{M}^{2}\right)-2 r M^{2}-\psi\left(M^{2}-M^{1}\right)=0 \\
\tilde{\pi}_{1}^{2}=Z-2\left(\tilde{L}^{2}+\tilde{M}^{2}\right)-\left(L^{2}+M^{2}\right)-2 w \tilde{L}^{2}=0 \\
\tilde{\pi}_{2}^{2}=Z-2\left(\tilde{L}^{2}+\tilde{M}^{2}\right)-\left(L^{2}+M^{2}\right)-2 r \tilde{M}^{2}-\psi\left(\tilde{M}^{2}-\tilde{M}^{1}\right)=0
\end{gathered}
$$

Solving these conditions delivers the period-two input choices $L^{2}, M^{2}, \tilde{L}^{2}, \tilde{M}^{2}$ as functions of $M^{1}$ and $\tilde{M}^{1}$. Let these functions be denoted by by $L^{2}\left(M^{1}, \tilde{M}^{1}\right)$, $M^{2}\left(M^{1}, \tilde{M}^{1}\right), \tilde{L}^{2}\left(\tilde{M}^{1}, M^{1}\right)$, and $\tilde{M}^{2}\left(\tilde{M}^{1}, M^{1}\right)$.

In period 1 , the two firms choose $L^{1}, M^{1}, \tilde{L}^{1}, \tilde{M}^{1}$ to maximise their discounted lifetime profits while taking into account potential strategic consequences in period 2 . That is, their objective functions will be equal to 
the instantaneous payoffs associated with their choice of management at time 1 and the continuation payoff, which is the payoff at time 2 . Firm $A^{\prime}$ s period- 1 objective is thus given by

$\pi^{1}\left(L^{1}, M^{1}, \tilde{L}^{1}, \tilde{M}^{1}\right)+\delta\left(\pi^{2}\left(L^{2}\left(M^{1}, \tilde{M}^{1}\right), M^{2}\left(M^{1}, \tilde{M}^{1}\right), \tilde{L}^{2}\left(\tilde{M}^{1}, M^{1}\right), \tilde{M}^{2}\left(\tilde{M}^{1}, M^{1}\right)\right)\right)$

Taking the first order conditions, we can solve for the (symmetric) equilibrium choices of worker and managerial inputs of the two firms.

\section{Numerical results}

To solve this game numerically, we assume the following parameters:

$$
Z=100 w=1 r=1 \psi=10
$$

The above game yields the a subgame-perfect equilibrium where.

$$
\begin{aligned}
& L^{1}=\tilde{L}^{1}=12.21 \\
& M^{1}=\tilde{M}^{1}=12.97 \\
& L^{2}=\tilde{L}^{2}=12.29 \\
& M^{2}=\tilde{M}^{2}=12.86
\end{aligned}
$$

In this example managers and workers have the same marginal products and marginal input costs. Therefore, the "cost minimising bundle" would involve equal amounts of managerial and worker inputs. In our example, the equilibrium management-to-worker ratio is greater than one, which implies over-management. This is driven by the fact that firms use period1 management as an instrument of strategic commitment. Given this observation, we now study an infinite horizon version of this model.

\subsection{Infinite horizon linear-quadratic example}

Now suppose that the two firms compete over infinitely many periods. Firm $A$ 's period- $t$ instantaneous profit is given by: 


$$
\begin{aligned}
\pi^{t}= & \left(Z-\left(\mu L^{t}+\eta M^{t}\right)-\left(\mu \tilde{L}^{t}+\eta \tilde{M}^{t}\right)\right)\left(\mu L^{t}+\eta M^{t}\right) \\
& -w\left(L^{t}\right)^{2}-r\left(M^{t}\right)^{2}-\frac{\psi}{2}\left(M^{t}-M^{t-1}\right)^{2}
\end{aligned}
$$

The instantaneous profit of firm $B$ is analogous.

The linear-quadratic specification suggests that there is a Markov-perfect equilibrium involving strategies that are linear functions of the state variables. We conjecture that these strategies are given by:

$$
\begin{aligned}
& M^{t}=f^{t}=\alpha_{1}+\beta_{1} M^{t-1}+\beta_{2} M^{\tilde{t}-1} \\
& \tilde{M}^{t}=\tilde{f_{t}}=\tilde{\alpha_{1}}+\tilde{\beta}_{1} \tilde{M}^{t-1}+\tilde{\beta}_{2} M^{t-1} \\
& L^{t}=g^{t}=\alpha_{2}+\beta_{3} M^{t-1}+\beta_{4} M^{\tilde{t}-1} \\
& \tilde{L}^{t}=\tilde{g}_{t}=\tilde{\alpha_{2}}+\tilde{\beta}_{3} \tilde{M}^{t-1}+\tilde{\beta}_{4} M^{t-1}
\end{aligned}
$$

Assuming $\mu=1$ and $\eta=1$, this conjecture implies that the profit of firm $A$ can be written as

$$
\begin{gathered}
\pi^{t}=\left(Z-\left(L^{t}+M^{t}\right)-\left(\tilde{\alpha_{2}}+\tilde{\beta}_{3} \tilde{M}^{t-1}+\tilde{\beta}_{4} M^{t-1}+\tilde{\alpha_{1}}+\tilde{\beta}_{1} \tilde{M}^{t-1}+\tilde{\beta}_{2} M^{t-1}\right)\right) \\
\left(L^{t}+M^{t}\right)-w\left(L^{t}\right)^{2}-r\left(M^{t}\right)^{2}-\frac{\psi}{2}\left(M^{t}-M^{t-1}\right)^{2}
\end{gathered}
$$

We have 12 unknown strategy parameters: $\alpha_{1}, \beta_{1}, \beta_{2}, \alpha_{2}, \beta_{3}, \beta_{4}, \tilde{\alpha}_{1}, \tilde{\beta}_{1}, \tilde{\beta}_{2}$, $\tilde{\alpha}_{2}, \tilde{\beta}_{3}, \tilde{\beta}_{4}$. We solve for these using the method of undetermined coefficients.

\subsubsection{The impact of the adjustment cost}

Once we find the equilibrium strategies, we can compute the steady state values of inputs and plot them as functions of the adjustment cost parameter $\psi$. We consider values of $\psi$ that are sufficiently high to guarantee stable MPE. The remaining parameters are as specified in the table below: 


$$
\begin{aligned}
& Z=100 \\
& \delta=0.9 \\
& w=1 \\
& r=1 \\
& \mu=1 \\
& \eta=1
\end{aligned}
$$

Figure 1 shows the steady state ratio of management to worker inputs:

How $M / L$ changes with the managerial transaction cost $\psi$

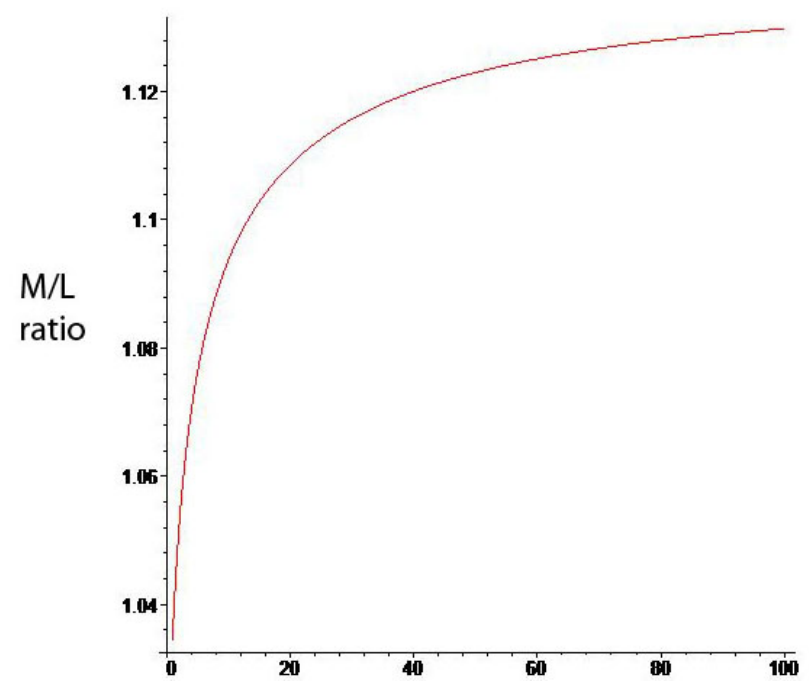

Figure 1

In an equivalent static game with zero adjustment costs, the cost minimising manager to worker ratio would be equal to 1 . Our figure shows that in the infinite horizon model, the steady state management to worker ratio always exceeds 1 . Therefore, the infinite horizon game generates overmanagement. Also, note that as the adjustment cost rises, the commitment value of the managerial input increases. Thus, the steady state management to worker ratio is increasing in $\psi$. 


\subsubsection{The impact of the discount factor}

Next we consider the implications of the discount factor for the ratio of management to worker inputs. Intuitively, the larger the discount factor is, the more the agent values future payoffs relative to current payoffs. This makes commitment to future output more valuable. Therefore, we would expect the ratio of management to worker inputs to be increasing in $\delta$.

We consider discount factors between 0.35 and 1 . The value of $\psi$ is set at 10. The remaining parameters are as specified in the table above.

\section{How $M / L$ changes with the discount factor $\delta$}

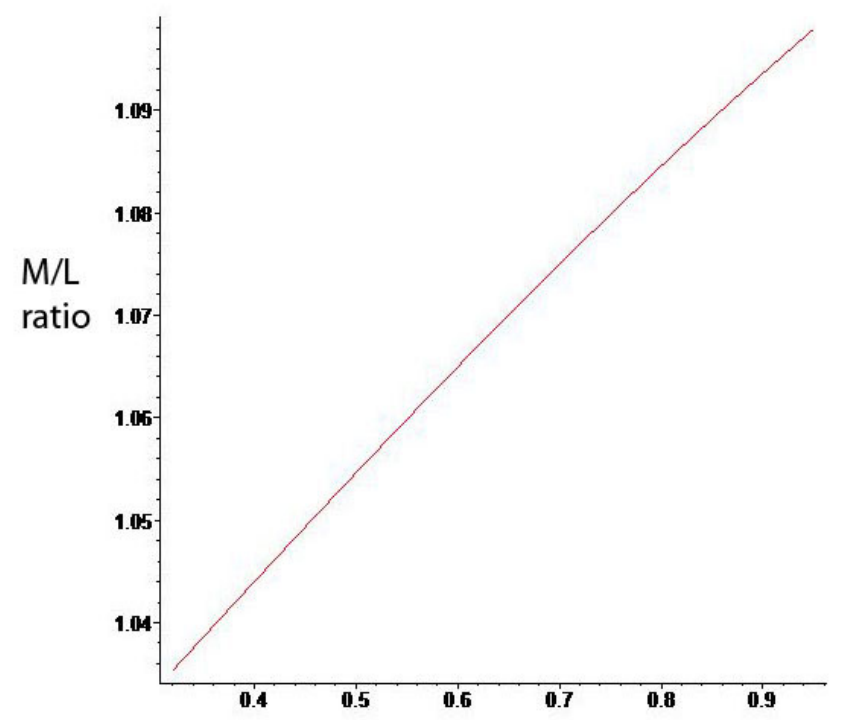

Figure 2

Figure 2 confirms that the steady-state management to worker ratio rises as the discount factor increases.

\subsubsection{The impact of product heterogeneity}

One final relationship of interest is the level of substitutability between products. Intuitively, the more heterogeneous the two products are, the 
less impact the firm's choice has on the marginal revenue of its opponent. As a result, the more heterogenous the product, the less scope there is for commitment.

To model product heterogeneity, we assume that firm $A^{\prime}$ 's inverse demand in period $t$ is given by:

$$
p^{t}=Z-x^{t}-\chi \tilde{x}^{t},
$$

where $\chi \in(0,1)$. The higher the value of $\chi$, the higher the degree of substitutability. At $\chi=0$ the firms are monopolists in their own markets, so there should be no commitment motive. At $\chi=1$ the firms are selling homogenous goods, so we revert to the formulation analysed previously.

We set $\psi=10$ and $\delta=0.9$, while the other parameters are unchanged. The steady-state management to worker ratio is plotted in the graph below:

How $M / L$ changes with the degree of product heterogeneity $\chi$

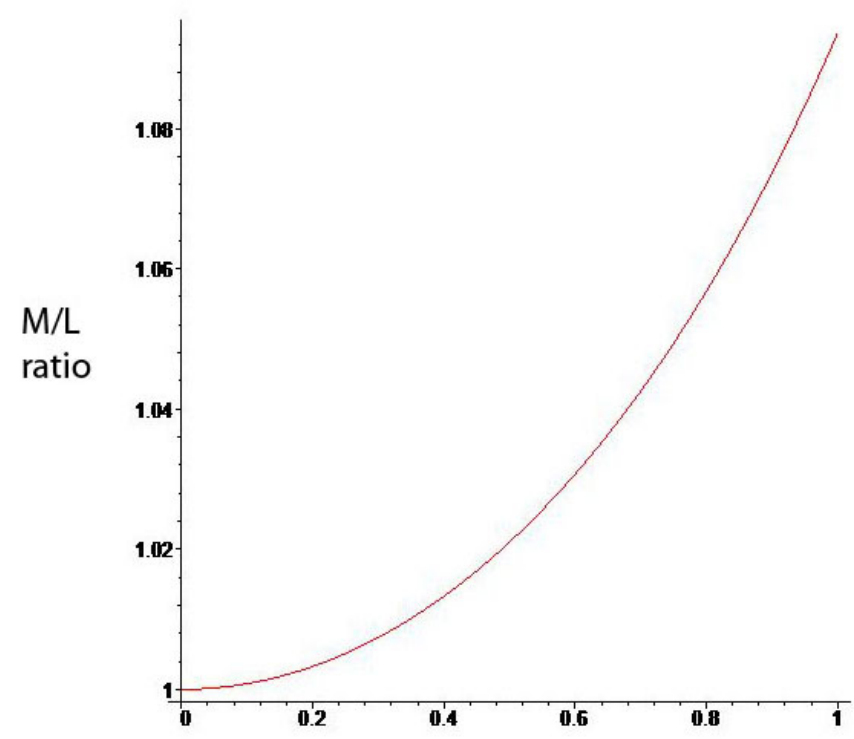

Figure 3

As expected, a higher $\chi$ leads to a higher management to worker ratio. Furthermore, when $\chi=0$ the management to worker ratio is equal to the cost minimising ratio of 1 . 


\subsection{Conclusion}

The dynamic framework provides a more satisfying view of what causes over-management in retail firms. By showing that over-management still occurs when the horizon of the game is extended indefinitely we have extended the number of situations where our results hold. Furthermore, fitting the result of over-management into a framework that does not presuppose strict irreversibility or observability of inputs also adds to the degree of realism surrounding our conclusions. 


\section{Chapter 6}

\section{Conclusion}

The preceding chapters discussed the strategic investment approach to explaining over-management. In economics, the cost of labour is often viewed as a simple variable cost. My thesis argues that this is not always the case. Some categories of labour inputs could be costly and difficult to adjust. As a result of costly adjustment, firms' choices of labour inputs involve more than a decision on what bundle of labour types is required to minimise costs. In particular, there could be a strategic motive behind the decisions to hire skilled and unskilled labour.

The two models presented here offer a testable hypothesis about strategic commitment. This enables us to verify whether over-management holds up in reality. Some potential ways of testing the hypothesis of retail overmanagement are described in Appendix C.

The labour input is difficult to study, since its productivity directly depends on interaction between agents. However, the distinction between skilled and unskilled labour goes some way in explaining the labour policies of oligopolistic firms. At a macro level, these strategic considerations provide insight into the behaviour of the labour market in an economy with aggregate shocks.

Fundamentally, we have shown that there is a strategic investment incentive for the hiring of skilled labour. Further research questions that may be asked along these lines are as follows.

- Empirical testing to see if over-management/commitment does oc- 
cur,

- Numerical work on a non-linear specification of the infinite horizon model (fundamentally with non-linear strategy functions).

- Exploring the interaction of the labour input with other input types for the firm (capital and resources).

- Considering imperfect observability and introducing expectations regarding other firms' labour inputs.

- A comparison with other phenomena in the labour market that could create over-management. 


\section{Chapter 7}

\section{Appendix}

\subsection{Appendix A}

After substitution of the worker strategies in the stage-1 payoff of firm $i \in\{A, B\}$, we obtain the following payoff functions:

$$
\begin{aligned}
\pi_{i}= & \left(1-\frac{M_{i}\left(M_{j}+0.2\right)+M_{j}\left(M_{i}+0.2\right)}{3 M_{i} M_{j}+0.4 M_{j}+0.4 M_{i}+0.04}\right) \frac{M_{i}\left(M_{j}+0.2\right)}{\left(3 M_{i} M_{j}+0.4 M_{j}+0.4 M_{i}+0.04\right)} \\
& -0.2 M_{i}-0.1 \frac{M_{i}\left(M_{j}+0.2\right)^{2}}{\left(3 M_{i} M_{j}+0.4 M_{j}+0.4 M_{i}+0.04\right)^{2}} .
\end{aligned}
$$

Differentiating these with respect to the firm's management input yields the first-order conditions

$$
\begin{gathered}
-33125 M_{i} M_{j}{ }^{3}+337500 M_{i}{ }^{2} M_{j}{ }^{3}+123750 M_{i}{ }^{2} M_{j}{ }^{2}+15000 M_{i}{ }^{2} M_{j}+600 M_{i}{ }^{2} \\
-4250 M_{j}{ }^{3}+2000 M_{i}^{3}+843750 M_{i}^{3} M_{j}{ }^{3}+337500 M_{i}^{3} M_{j}{ }^{2}+45000 M_{i}{ }^{3} M_{j} \\
-22500 M_{i} M_{j}{ }^{2}-2525 M_{j}{ }^{2}-190 M_{i}-23-440 M_{j}-3975 M_{i} M_{j}=0
\end{gathered}
$$

and 


$$
\begin{gathered}
45000 M_{i} M_{j}^{3}+337500 M_{i}^{2} M_{j}^{3}+123750 M_{i}^{2} M_{j}^{2}-22500 M_{i}^{2} M_{j} \\
-2525 M_{i}^{2}+2000 M_{j}^{3}-4250 M_{i}^{3}+843750 M_{i}^{3} M_{j}^{3}+337500 M_{i}^{3} M_{j}{ }^{2}-33125 M_{i}^{3} M \\
15000 M_{i} M_{j}{ }^{2}+600 M_{j}{ }^{2}-440 M_{i}-190 M_{j}-3975 M_{i} M_{j}-23=0 .
\end{gathered}
$$

This system of equations has nine potential solutions. However, management levels have to be positive. Moreover, the solution has to be a real number. Finally, our game is symmetric, so we know that in equilibrium $M_{i}=M_{j}$. Only one of the solutions satisfies these requirements. It is given by

$$
M_{i}^{*}=M_{j}^{*}=0.1965087033 .
$$

Substituting the equilibrium management levels, we obtain

$$
\begin{gathered}
L_{i}^{*}=L_{j}^{*}=0.3152454277 . \\
x_{i}=x_{j}=0.2488944962 .
\end{gathered}
$$

\subsection{Appendix B}

\subsubsection{Increasing the number of firms}

So far we have assumed a duopolistic industry. We can generalise our setting to $n$ firms as follows.

Consider an arbitrary firm $i, i \in(1, n)$. Its revenue function is now $R^{i}=$ $R^{i}\left(f^{1}, f^{2}, \ldots, f^{n}\right)$. Firm $i^{\prime}$ s payoff function takes the form

$$
\pi^{i}=R^{i}-w L^{i}-r M^{i}
$$

The first-order conditions for the worker input is

$$
\frac{\partial \pi^{i}}{\partial L^{i}}=\frac{\partial R^{i}}{\partial x^{i}} \frac{\partial f^{i}}{\partial L^{i}}-w=0
$$


In the static game, the first-order condition for management is given by

$$
\frac{\partial \pi^{i}}{\partial M^{i}}=\frac{\partial R^{i}}{\partial x^{i}} \frac{\partial f^{i}}{\partial M^{i}}-r=0 .
$$

In the sequential game, the first-order conditions for the subgame-perfect equilibrium choice of management are

$$
\frac{\partial \pi^{i}}{\partial M^{i}}=\frac{\partial R^{i}}{\partial x^{i}} \frac{\partial f^{i}}{\partial L^{i}} \frac{\partial L^{i}}{\partial M^{i}}+\frac{\partial R^{i}}{\partial x^{i}} \frac{\partial f^{i}}{\partial M^{i}}+\sum_{j \neq i} \frac{\partial R^{i}}{\partial x^{j}} \frac{\partial f^{j}}{\partial L^{j}} \frac{\partial L^{j}}{\partial M^{i}}-w \frac{\partial L^{i}}{\partial M^{i}}-r=0 .
$$

Taking into account that the worker input is chosen optimally, these firstorder conditions can be rewritten as

$$
\frac{\partial \pi^{i}}{\partial M^{i}}=\frac{\partial R^{i}}{\partial x^{i}} \frac{\partial f^{i}}{\partial M^{i}}+\sum_{j \neq i} \frac{\partial R^{i}}{\partial x^{j}} \frac{\partial f^{j}}{\partial L^{j}} \frac{\partial L^{j}}{\partial M^{i}}-r=0 .
$$

This indicates that the result of over-management still depends on the sign of $\partial L^{j} / \partial M^{i}$.

\subsection{Appendix C}

If a firm's choice of inputs does not minimise costs, it is possible that this firm may be using inputs for strategic commitment. This hypothesis is difficult thing to test for, given the huge variety of possible revenue functions and production functions that firms may face. However, it is possible to circumvent these problems by way of a non-parametric test for cost-minimisation.

This approach was first suggested by Hanoch \& Rothschild (1972) and Varian (1984). Simply put, the test looks through the data to see if there at any point more inputs have been used to create a level of output relative to prior observed data. Varian calls this the weak axiom of cost minimization.

Ray (2004) noted that this type of test may not be appropriate because of volatility in the production process. Fundamentally, the transition from inputs to outputs may involve some error resulting from the difference between ex-ante expectations and ex-post outcomes. His solution is to 
estimate how large the conceivable error could be to make the data satisfy the weak axiom of cost minimization. We then have to ask, is this level of error in the production process believable?

In the case of department stores our final output is actually sales, implying that a fair level of volatility in the creation of outputs from a given set of inputs is believable. Therefore, any test would have to take into consideration unpredictable shifts in demand.

\subsection{Appendix D}

\subsubsection{Deriving Firm A's Euler equation}

The Bellman equation of firm $A$ is

$$
\begin{aligned}
V\left(M^{t-1}, \tilde{M}^{t-1}\right)= & \max _{L^{t}, M^{t}}\left\{\pi^{t}\left(L^{t}, M^{t}, \tilde{g}^{t}\left(\tilde{M}^{t-1}, M^{t-1}\right), \tilde{f}^{t}\left(\tilde{M^{t-1}}, M^{t-1}\right), M^{t-1}, \tilde{M}^{t-1}\right)\right. \\
& \left.+\delta V\left(M^{t}, \tilde{f}^{t}\left(M^{t-1}, M^{t-1}\right)\right)\right\} .
\end{aligned}
$$

The first-order conditions with respect to $L^{t}$ and $M^{t}$ are

$$
\begin{gathered}
0=\pi_{1}^{t} \\
0=\pi_{2}^{t}+\delta V_{1}^{t+1} .
\end{gathered}
$$

Solving for the derivative of the value function gives us

$$
V_{1}^{t+1}=-\frac{\pi_{2}^{t}}{\delta} .
$$

Since the value function is time invariant, it must be true that

$$
V_{1}^{t}=-\frac{\pi_{2}^{t-1}}{\delta} .
$$


Differentiation with respect to $M^{t}$ and $M^{t-1}$ yields the following envelope conditions

$$
\begin{aligned}
& V_{1}^{t}=\pi_{3}^{t} \tilde{g}_{2}^{t}+\pi_{4}^{t} \tilde{f}_{2}^{t}+\pi_{5}^{t}+\delta V_{2}^{t+1} \tilde{f}_{2}^{t} \\
& V_{2}^{t}=\pi_{3}^{t} \tilde{g}_{1}^{t}+\pi_{4}^{t} \tilde{f}_{1}^{t}+\pi_{6}^{t}+\delta V_{2}^{t+1} \tilde{f}_{1}^{t}
\end{aligned}
$$

Substituting the derivative of the value function from the first-order condition delivers

$$
-\frac{\pi_{2}^{t-1}}{\delta}=\pi_{3}^{t} \tilde{g}_{2}^{t}+\pi_{4}^{t} \tilde{f}_{2}^{t}+\pi_{5}^{t}+\delta V_{2}^{t+1} \tilde{f}_{2}^{t}
$$

We can solve this condition for $V_{2}^{t+1}$ :

$$
V_{2}^{t+1}=-\frac{1}{\delta \tilde{f}_{2}^{t}}\left(\frac{\pi_{2}^{t-1}}{\delta}+\pi_{3}^{t} \tilde{g}_{2}^{t}+\pi_{4}^{t} \tilde{f}_{2}^{t}+\pi_{5}^{t}\right) .
$$

Again, stationarity of the value function implies

$$
V_{2}^{t}=-\frac{1}{\delta \tilde{f}_{2}^{t-1}}\left(\frac{\pi_{2}^{t-2}}{\delta}+\pi_{3}^{t-1} \tilde{g}_{2}^{t-1}+\pi_{4}^{t-1} \tilde{f}_{2}^{t-1}+\pi_{5}^{t-1}\right)
$$

Putting together equations 7.10, 7.11, and 7.12 gives us:

$$
\begin{gathered}
-\frac{1}{\delta \tilde{f}_{2}^{t-1}}\left(\frac{\pi_{2}^{t-2}}{\delta}+\pi_{3}^{t-1} \tilde{g}_{2}^{t-1}+\pi_{4}^{t-1} \tilde{f}_{2}^{t-1}+\pi_{5}^{t-1}\right)= \\
\pi_{3}^{t} \tilde{g}_{1}^{t}+\pi_{4}^{t} \tilde{f}_{1}^{t}+\pi_{6}^{t}-\frac{f_{1}^{t}}{\tilde{f}_{2}^{t}}\left(\frac{\pi_{2}^{t-1}}{\delta}+\pi_{3}^{t} \tilde{g}_{2}^{t}+\pi_{4}^{t} \tilde{f}_{2}^{t}+\pi_{5}^{t}\right) .
\end{gathered}
$$

Finally, we move the time subscript forward by 2 periods, and multiply by $\delta^{2} \tilde{f}_{2}^{t+1}$ to obtain 


$$
\begin{aligned}
0= & \pi_{2}^{t}+\delta\left(\pi_{3}^{t+1} \tilde{g}_{2}^{t+1}+\pi_{4}^{t+1} \tilde{f}_{2}^{t+1}+\pi_{5}^{t+1}\right)+\delta^{2} \tilde{f}_{2}^{t+1}\left(\pi_{3}^{t+2} \tilde{g}_{1}^{t+2}+\pi_{4}^{t+2} \tilde{f}_{1}^{t+2}+\pi_{6}^{t+2}\right) \\
& -\frac{\delta f_{2}^{t+1} f_{1}^{t+2}}{\tilde{f}_{2}^{t+2}}\left(\frac{\pi_{2}^{t+1}}{\delta}+\pi_{3}^{t+2} \tilde{g}_{2}^{t+2}+\pi_{4}^{t+2} \tilde{f}_{2}^{t+2}+\pi_{5}^{t+2}\right) .
\end{aligned}
$$

\subsection{Appendix E}

\subsubsection{Euler equations for the four state model}

First-Order Conditions and Envelope Conditions

Firm A's first-order conditions are:

$$
\begin{aligned}
& 0=\pi_{1}^{t}+\delta V_{1}^{t+1} \\
& 0=\pi_{2}^{t}+\delta V_{2}^{t+1} .
\end{aligned}
$$

The envelope condition for $L^{t-1}$ is

$$
V_{1}^{t}=\pi_{3}^{t} \tilde{g}_{3}^{t}+\pi_{4}^{t} \tilde{f}_{3}^{t}+\pi_{5}^{t}+\delta\left(V_{3}^{t+1} \tilde{g}_{3}^{t}+V_{4}^{t+1} \tilde{f}_{3}^{t}\right) .
$$

The envelope condition for $M^{t-1}$ is

$$
V_{2}^{t}=\pi_{3}^{t} \tilde{g}_{4}^{t}+\pi_{4}^{t} \tilde{f}_{4}^{t}+\pi_{6}^{t}+\delta\left(V_{3}^{t+1} \tilde{g}_{4}^{t}+V_{4}^{t+1} \tilde{f}_{4}^{t}\right) .
$$

The envelope condition for $\tilde{L}^{t-1}$ is

$$
V_{3}^{t}=\pi_{3}^{t} \tilde{g}_{1}^{t}+\pi_{4}^{t} \tilde{f}_{1}^{t}+\delta\left(V_{3}^{t+1} \tilde{g}_{1}^{t}+V_{4}^{t+1} \tilde{f}_{1}^{t}\right) .
$$

The envelope condition for $\tilde{M}^{t-1}$ is

$$
V_{4}^{t}=\pi_{3}^{t} \tilde{g}_{2}^{t}+\pi_{4}^{t} \tilde{f}_{2}^{t}+\delta\left(V_{3}^{t+1} \tilde{g}_{2}^{t}+V_{4}^{t+1} \tilde{f}_{2}^{t}\right)
$$


Given stationarity, we can move around the time index. Lagging equation 2 and rearranging yields

$$
V_{1}^{t}=-\frac{\pi_{1}^{t-1}}{\delta} .
$$

Similarly from equation 3 we get

$$
V_{2}^{t}=-\frac{\pi_{2}^{t-1}}{\delta} .
$$

We substitute $V_{1}^{t}$ and $V_{2}^{t}$ from equations 8 and 9 into equations 5 and 6 . This gives us

$$
-\frac{\pi_{1}^{t-1}}{\delta}=\pi_{3}^{t} \tilde{g}_{3}^{t}+\pi_{4}^{t} \tilde{f}_{3}^{t}+\pi_{5}^{t}+\delta\left(V_{3}^{t+1} \tilde{g}_{3}^{t}+V_{4}^{t+1} \tilde{f}_{3}^{t}\right)
$$

and

$$
-\frac{\pi_{2}^{t-1}}{\delta}=\pi_{3}^{t} \tilde{g}_{4}^{t}+\pi_{4}^{t} \tilde{f}_{4}^{t}+\pi_{6}^{t}+\delta\left(V_{3}^{t+1} \tilde{g}_{4}^{t}+V_{4}^{t+1} \tilde{f}_{4}^{t}\right) .
$$

In matrix form, these conditions can be written as

$$
\left[\begin{array}{ll}
\delta \tilde{g}_{3}^{t} & \delta \tilde{f}_{3}^{t} \\
\delta \tilde{g}_{4}^{t} & \delta \tilde{f}_{4}^{2}
\end{array}\right]\left[\begin{array}{l}
V_{3}^{t+1} \\
V_{4}^{t+1}
\end{array}\right]=\left[\begin{array}{l}
-\left(\frac{\pi_{1}^{t-1}}{\delta}+\pi_{3}^{t} \tilde{g}_{3}^{t}+\pi_{4}^{t} \tilde{f}_{3}^{t}\right) \\
-\left(\frac{\pi_{2}^{t-1}}{\delta}+\pi_{3}^{t} \tilde{g}_{4}^{t}+\pi_{4}^{t} \tilde{f}_{4}^{t}\right)
\end{array}\right] .
$$

Use the Cramer rule to solve for $V_{3}^{t+1}$ and $V_{4}^{t+1}$ :

$$
\begin{aligned}
V_{3}^{t+1} & =\frac{\tilde{f}_{3}^{t}\left(\frac{\pi_{2}^{t-1}}{\delta}+\pi_{3}^{t} \tilde{g}_{4}^{t}+\pi_{4}^{t} \tilde{f}_{4}^{t}\right)-\tilde{f}_{4}^{t}\left(\frac{\pi_{1}^{t-1}}{\delta}+\pi_{3}^{t} \tilde{g}_{3}^{t}+\pi_{4}^{t} \tilde{f}_{3}^{t}\right)}{\tilde{g}_{3}^{t} \tilde{f}_{4}^{t}-\tilde{g}_{4}^{t} \tilde{f}_{3}^{t}} \\
V_{4}^{t+1} & =\frac{\tilde{g}_{4}^{t}\left(\frac{\pi_{1}^{t-1}}{\delta}+\pi_{3}^{t} \tilde{g}_{3}^{t}+\pi_{4}^{t} \tilde{f}_{3}^{t}\right)-\tilde{g}_{3}^{t}\left(\frac{\pi_{2}^{t-1}}{\delta}+\pi_{3}^{t} \tilde{g}_{4}^{t}+\pi_{4}^{t} \tilde{f}_{4}^{t}\right)}{\tilde{g}_{3}^{t} \tilde{f}_{4}^{t}-\tilde{g}_{4}^{t} \tilde{f}_{3}^{t}} .
\end{aligned}
$$




\section{Labour Euler Equation}

The labour Euler equation can be derived by substituting equations 7.22 and 7.23 into equation 7.16. In order to remove the value function from the Euler equation, a lagged version of equation 7.22 is required. It can be found using stationarity:

$$
V_{3}^{t}=\frac{\tilde{f}_{3}^{t-1}\left(\frac{\pi_{2}^{t-2}}{\delta}+\pi_{3}^{t-1} \tilde{g}_{4}^{t-1}+\pi_{4}^{t-1} \tilde{f}_{4}^{t-1}\right)-\tilde{f}_{4}^{t-1}\left(\frac{\pi_{1}^{t-2}}{\delta}+\pi_{3}^{t-1} \tilde{g}_{3}^{t-1}+\pi_{4}^{t-1} \tilde{f}_{3}^{t-1}\right)}{\tilde{g}_{3}^{t-1} \tilde{f}_{4}^{t-1}-\tilde{g}_{4}^{t-1} \tilde{f}_{3}^{t-1}} .
$$

In order to simplify notation, we set $\frac{\pi_{1}^{t-1}}{\delta}+\pi_{3}^{t} \tilde{g}_{3}^{t}+\pi_{4}^{t} \tilde{f}_{3}^{t}=X_{1}^{t}$ and $\frac{\pi_{2}^{t-1}}{\delta}+\pi_{3}^{t} \tilde{g}_{4}^{t}+$ $\pi_{4}^{t} \tilde{f}_{4}^{t}=X_{2}^{t}$. Putting this all together and moving forward two periods in time gives:

$$
\begin{aligned}
0= & X_{1}^{t+1}-\frac{\tilde{f}_{3}^{t+1}}{f_{4}^{t+1}} X_{2}^{t+1}+\frac{\tilde{g}_{3}^{t+1} \tilde{f}_{4}^{t+1}-\tilde{g}_{4}^{t+1} \tilde{f}_{3}^{t+1}}{\tilde{f}_{4}^{t+1}}\left(\pi_{3}^{t+2} \tilde{g}_{1}^{t+2}+\pi_{4}^{t+2} \tilde{f}_{1}^{t+2}\right) \\
& +\frac{\delta \tilde{g}_{1}^{t+2}\left(\tilde{g}_{3}^{t+1} \tilde{f}_{4}^{t+1}-\tilde{g}_{4}^{t+1} \tilde{f}_{3}^{t+1}\right)}{\tilde{f}_{4}^{t+1}\left(\tilde{g}_{3}^{t+2} \tilde{f}_{4}^{t+2}-\tilde{g}_{4}^{t+2} \tilde{f}_{3}^{t+2}\right)}\left(\tilde{f}_{3}^{t+2} X_{2}^{t+2}-\tilde{f}_{4}^{t+2} X_{1}^{t+2}\right) \\
& +\frac{\delta \tilde{f}_{1}^{t+2}\left(\tilde{g}_{3}^{t+1} \tilde{f}_{4}^{t+1}-\tilde{g}_{4}^{t+1} \tilde{f}_{3}^{t+1}\right)}{\tilde{f}_{4}^{t+1}\left(\tilde{g}_{3}^{t+2} \tilde{f}_{4}^{t+2}-\tilde{g}_{4}^{t+2} \tilde{f}_{3}^{t+2}\right)}\left(\tilde{g}_{4}^{t+2} X_{1}^{t+2}-\tilde{g}_{3}^{t+2} X_{2}^{t+2}\right)
\end{aligned}
$$

\section{Management Euler Equation}

We substitute equations 7.22 and 7.23 into equation 7.17. We also need a lagged version of equation 7.23. Using stationarity, we obtain

$$
V_{4}^{t}=\frac{\tilde{g}_{4}^{t-1}\left(\frac{\pi_{1}^{t-2}}{\delta}+\pi_{3}^{t-1} \tilde{g}_{3}^{t-1}+\pi_{4}^{t-1} \tilde{f}_{3}^{t-1}\right)-\tilde{g}_{3}^{t-1}\left(\frac{\pi_{2}^{t-2}}{\delta}+\pi_{3}^{t-1} \tilde{g}_{4}^{t-1}+\pi_{4}^{t-1} \tilde{f}_{4}^{t-1}\right)}{\tilde{g}_{3}^{t-1} \tilde{f}_{4}^{t-1}-\tilde{g}_{4}^{t-1} \tilde{f}_{3}^{t-1}}
$$

Again, in order to simplify notation, we set $\frac{\pi_{1}^{t-1}}{\delta}+\pi_{3}^{t} \tilde{g}_{3}^{t}+\pi_{4}^{t} \tilde{f}_{3}^{t}=X_{1}^{t}$ and $\frac{\pi_{2}^{t-1}}{\delta}+\pi_{3}^{t} \tilde{g}_{4}^{t}+\pi_{4}^{t} \tilde{f}_{4}^{t}=X_{2}^{t}$. Putting this all together and moving forward two 
periods in time gives:

$$
\begin{aligned}
0= & X_{2}^{t+1}-\frac{\tilde{g}_{3}^{\tilde{t+1}}}{\tilde{g}_{4}^{t+1}} X_{1}^{t+1}+\frac{\tilde{g}_{3}^{t+1} \tilde{f}_{4}^{t+1}-\tilde{g}_{4}^{t+1} \tilde{f}_{3}^{t+1}}{\tilde{g}_{4}^{t+1}}\left(\pi_{3}^{t+2} \tilde{g}_{2}^{t+2}+\pi_{4}^{t+2} \tilde{f}_{2}^{t+2}\right) \\
& +\frac{\delta \tilde{g}_{2}^{t+2}\left(\tilde{g}_{3}^{t+1} \tilde{f}_{4}^{t+1}-\tilde{g}_{4}^{t+1} \tilde{f}_{3}^{t+1}\right)}{\tilde{g}_{4}^{t+1}\left(\tilde{g}_{3}^{t+2} \tilde{f}_{4}^{t+2}-\tilde{g}_{4}^{t+2} \tilde{f}_{3}^{t+2}\right)}\left(\tilde{f}_{3}^{t+2} X_{2}^{t+2}-\tilde{f}_{4}^{t+2} X_{1}^{t+2}\right) \\
& +\frac{\delta \tilde{f}_{2}^{t+2}\left(\tilde{g}_{3}^{t+1} \tilde{f}_{4}^{t+1}-\tilde{g}_{4}^{t+1} \tilde{f}_{3}^{t+1}\right)}{\tilde{g}_{4}^{t+1}\left(\tilde{g}_{3}^{t+2} \tilde{f}_{4}^{t+2}-\tilde{g}_{4}^{t+2} \tilde{f}_{3}^{t+2}\right)}\left(\tilde{g}_{4}^{t+2} X_{1}^{t+2}-\tilde{g}_{3}^{t+2} X_{2}^{t+2}\right) .
\end{aligned}
$$




\section{Bibliography}

Alchian, A. \& Demsetz, H. (1972), 'Production, information costs, and economic organization', The American Economic Review 62(5), 777-795.

Bertrand, J. (1883), Book review of theorie mathematique de la richesse sociale and of recherches sur les principles mathematiques de la theorie des richesses, Vol. 67, Journal da Savants.

Brander, J. A. \& Spencer, B. J. (1983), 'Strategic commitment with r\&d: The symmetric case', The Bell Journal of Economics 14(1), 225-235.

Brock, W. A. \& Scheinkman, J. A. (1985), 'Price setting supergames with capacity constraints', The Review of Economic Studies 52(3), 371-382.

Cabral, L. M. B. (2000), Introduction to Industrial Organisation, MIT Press.

Calvo, G. A. \& Wellisz, S. (1978), 'Supervision, loss of control, and the optimum size of the firm', The Journal of Political Economy 86(5), 943952.

Calvo, G. A. \& Wellisz, S. (1979), ‘Hierarchy, ability, and income distribution', The Journal of Political Economy 87(5), 991-1010.

Cournot, A. A. (1897), Recherches sur les principes mathmatiques de la thorie des richesses (Researches into the Mathematical Principles of the Theory of Wealth), N.T. Bacon. Initially published in French in 1838.

Coury, T. \& Petkov, V. P. (2007), Independence, accountability, and credibility of monetary policy. Working Paper.

Dixit, A. (1997), 'Investment and employment dynamics in the short run and the long run', Oxford Economic Papers 49, 1-20. 
Dixit, A. K. \& Pindyck, R. S. (1995), The new option view of investment. Working Paper Draft 3794-95-EFA.

Dixon, H. (1986), 'Strategic investment with consistent conjectures', Oxford Economic Papers, New Series 38(Supplement: Strategic Behaviour and Industrial Competition), 111-128.

Dragan, G. (n.d.), Supporting collusion with insufficient capacity. 2004.

Fershtman, C. \& Judd, K. L. (1987), 'Equilibrium incentives and oligopoly', The American Economic Review 77, 927-940.

Fershtman, C. \& Kalai, E. (1993), 'Complexity consideration and market behavior', The RAND Journal of Economics 24(2), 224-235.

Fischer, O. J. B. S. (1989), Lectures on Macroeconomics, The MIT Press.

Fudenberg, D. \& Tirole, J. (1996), Game Theory, The MIT Press.

Green, E. J. \& Porter, R. H. (1984), 'Noncooperative collusion under imperfect price information', Econometrica 52(1), 87-100.

Greenberg, J. (1990), The Theory of Social Situations, Cambridge University Press.

Hamminga, B. (1982), Philosophy of Economics, Springer.

Hanoch, G. \& Rothschild, M. (1972), 'Testing the assumptions of production theory: A nonparametric approach', The Journal of Political Economy 80(2), 256-275.

Holmstrom, B. (1982), 'Moral hazard in teams', The Bell Journal of Economics 13(2), 324-340.

Holstrom, B. \& Milgrom, P. (1991), 'Multi-task principal-agent analyses: incentive contracts, asset ownership, and job design', Journal of Law, Economics and Organization 7, 24-52.

Ivaldi, M., Jullien, B., Rey, P., Seabright, P. \& Tirole, J. (2003), The economics of tacit collusion, Technical report, DG Competition, European Commission. 
Jensen, M. C. \& Meckling, W. H. (1976), 'Theory of the firm: Managerial behavior, agency costs and ownership structure', Journal of Financial Economics 3(4), 305-360.

Jun, B. \& Vives, X. (2001), 'Incentives in dynamic duopoly', CEPR 2899, 1-.

Jun, B. \& Vives, X. (2004), 'Strategic incentives in dynamic duopoly', Journal of Economic Theory 116, 249-281.

Keren, M. \& Levhari, D. (1983), 'The internal organization of the firm and the shape of average costs', The Bell Journal of Economics 14(2), 474486.

Machin, S. \& Manning, A. (1992), ‘Testing dynamic models of worker effort', Journal of Labor Economics 10(3), 288-305.

Maki, U. (1994), New Directions in Economic Methodology, Routledge.

McCallum, B. T. (1999), 'Role of the minimal state variable criterion in rational expectations models', National Bureau of Economic Research NA, $1-33$.

Ray, S. C. (2004), A simple statistical test of violation of theweak axiom of cost minimization. Working Paper.

Reynolds, S. S. (1987), 'Capacity investment, preemption and commitment in an infinite horizon model', International Economic Review 28, 69-88.

Rosen, S. (1982), 'Authority, control, and the distribution of earning', The Bell Journal of Economics 13(2), 311-323.

Rubinstein, A. (1991), 'Comments on the interpretation of game theory', Econometrica 59(4), 909-924.

Shapiro, C. \& Stiglitz, J. E. (1984), 'Equilibrium unemployment as a worker discipline device', The American Economic Review 74(3), 433-444.

Skilivas, S. D. (1987), 'The strategic choice of managerial incentives', RAND Journal of Economics 18(3), 452-458.

Spence, A. M. (1977), 'Entry, capacity, investment and oligopolistic pricing', The Bell Journal of Economics 8(2), 534-544. 
Varian, H. R. (1984), 'The nonparametric approach to production analysis', Econometrica 52(3), 579-598.

Watson, J. (2002), Strategy: An introduction to game theory, Norton \& Company.

Williamson, O. (1967), 'Hierarchical control and optimum firm size', The Journal of Political Economy 75(2), 123-138. 